\title{
On the Angola Low Interannual Variability and Its Role in Modulating ENSO Effects in Southern Africa 0
}

\author{
SAlvatore Pascale \\ Program in Atmospheric and Oceanic Sciences, Princeton University, and NOAA/Geophysical Fluid Dynamics \\ Laboratory, Princeton, New Jersey \\ BENJAMIN POHL \\ Centre de Recherches de Climatologie, UMR 6282 Biogéosciences, CNRS/Université de Bourgogne \\ Franche-Comté, Dijon, France \\ SARAH B. KAPNICK \\ NOAA/Geophysical Fluid Dynamics Laboratory, Princeton, New Jersey \\ HONGHAI ZHANG ${ }^{\text {a }}$ \\ Program in Atmospheric and Oceanic Sciences, Princeton University, Princeton, New Jersey
}

(Manuscript received 31 October 2018, in final form 29 April 2019)

\begin{abstract}
The Angola low is a summertime low pressure system that affects the convergence of low-level moisture fluxes into southern Africa. Interannual variations of the Angola low reduce the seasonal prediction skills for this region that arise from coupled atmosphere-ocean variability. Despite its importance, the interannual dynamics of the Angola low, and its relationship with El Niño-Southern Oscillation (ENSO) and other coupled modes of variability, are still poorly understood, mostly because of the scarcity of atmospheric data and short-term duration of atmospheric reanalyses in the region. To bypass this issue, we use a long-term (3500 year) run from a 50-km-resolution global coupled model capable of simulating the summertime southern African large-scale circulation and teleconnections. We find that the meridional displacement and strength of the Angola low are moderately modulated by local sea surface temperature anomalies, especially those in proximity of the southeastern African coast, and to a lesser extent by ENSO and the subtropical Indian Ocean dipole. Comparison of the coupled run with a 1000 -yr run driven by climatological sea surface temperatures reveals that the interannual excursions of the Angola low are in both cases associated with geopotential height anomalies over the southern Atlantic and Indian Ocean related to extratropical atmospheric variability. Midlatitude atmospheric variability explains almost $60 \%$ of the variance of the Angola low variability in the uncoupled run, but only $20 \%$ in the coupled run. Therefore, while the Angola low appears to be intrinsically controlled by atmospheric extratropical variability, the interference of the atmospheric response forced by sea surface temperature anomalies weakens this influence.
\end{abstract}

Supplemental information related to this paper is available at the Journals Online website: https://doi.org/10.1175/JCLI-D-180745.s1.

\footnotetext{
${ }^{\text {a }}$ Current affiliation: Lamont-Doherty Earth Observatory, Palisades, New York.
}

Corresponding author: Salvatore Pascale, salvatore.pascale@ noaa.gov

\section{Introduction}

Southern Africa (SA, here loosely defined as the African continental land south of $15^{\circ} \mathrm{S}$ ) summer rainfall experiences large interannual and decadal variability (e.g., Reason et al. 2006; Dieppois et al. 2016), which often results in prolonged multiannual dry periods. These droughts have particularly detrimental impacts on local SA communities, largely dependent on rain-fed subsistence agriculture, natural ecosystems and wildlife 
(Conway et al. 2015). For example, the recent 2015/16 drought was one of the most severe on record (Blamey et al. 2018) and caused reductions in runoff, unusually low lake levels, record-high temperatures, water supply disruption, and hydroelectric load shedding in large parts of southern Africa (Siderius et al. 2018). This extreme event highlights the need to predict substantial seasonal rainfall anomalies months in advance for local governments and communities to manage water resources and energy infrastructures.

It has long been noted that interannual variability of SA rainfall correlates with El Niño-Southern Oscillation (ENSO) (e.g., Ropelewski and Halpert 1987; Nicholson and Entekhabi 1987; Lindesay 1988). El Niño (La Niña) years are typically associated with below-average (above-average) rainfall in SA. The ENSO signal provides most of the skill we have for seasonal prediction of SA summer rainfall (Landman and Beraki 2012; Beraki et al. 2014; Pomposi et al. 2018). Yet, ENSO explains a relatively small fraction of all seasonal rainfall anomalies (e.g., Lyon and Mason 2007; Fauchereau et al. 2009; Pohl et al. 2009). For example, during the strong 1997/98 El Niño, widespread drought conditions failed to materialize in January-March, with seasonal rainfall amounts close to normal over most of SA (Lyon and Mason 2007). El Niño events that occurred in 1953, 1957, 1976, 1997 and 2010 were also not associated with drought conditions in SA (Nicholson and Kim 1997; Pomposi et al. 2018; Driver et al. 2019; Blamey et al. 2018). Diversity in the response of SA summer variability to ENSO has been attributed to the different flavors of El Niño (Ratnam et al. 2014) and to the diversity of the global sea surface temperature (SST) expressions of ENSO (e.g., Johnson 2013), that is, to nterfering effects of the concomitant SSTs anomalies in the Indian and Atlantic Oceans (Goddard and Graham 1999; Misra 2003; Hoell et al. 2015). More specifically, positive (negative) SST anomalies in the Indian Ocean were indicated as a necessary prerequisite to have the expected rainfall response to El Niño (La Niña) over Africa (Nicholson 2003). Beyond the role of the tropical oceans, the subtropical Indian Ocean dipole (SIOD; Behera and Yamagata 2001), which in its positive phase is characterized by positive SST anomalies to the southeast of Madagascar and negative SST anomalies to the east of Madagascar, is also believed to be important for the SA summer rainfall (Reason 2002; Washington and Preston 2006). Hoell et al. (2017) invoke the role of the SIOD in weakening the atmospheric response to ENSO when these two modes have the same phase. Yet, the aforementioned 1997/98 summer did feature a strong El Niño, positive anomalies in the Indian Ocean and a negative phase of the SIOD, but still drought conditions did not materialize.

Reason and Jagadheesha (2005) and Lyon and Mason (2007) first pointed out that during the $1997 / 98$ El Niño the SA summer was characterized by an unusually strong and southward displaced Angola low, a low-level low pressure system with minimum at about $14^{\circ} \mathrm{S}$ centered over southeastern Angola. This was atypical, as during El Niño years (e.g., 1982/83 and 2015/16) the Angola low tends to be anomalously weak (Blamey et al. 2018). The Angola low develops in October-November as heat low associated with dry convection driven by intense surface heating (e.g., Rácz and Smith 1999). In December it then develops a vertical structure dominated by moist convection (Munday and Washington 2017; Howard and Washington 2018) typical of a tropical low, which specifically resembles that of monsoon lows (e.g., Hurley and Boos 2015). The Angola low modulates the convergence of low-level moisture fluxes into SA by controlling westerly moisture fluxes from the tropical Atlantic and easterly and northwesterly moisture fluxes from the southwestern tropical Indian Ocean and the Congo basin (Cook et al. 2004; Vigaud et al. 2009). Synoptic and subseasonal variations in the location of the Angola low can have important effects on SA rainfall by impacting the formation and position of tropical-temperate troughs (Mulenga 1998; Cook et al. 2004; Reason and Jagadheesha 2005).

Using three different reanalyses, Crétat et al. (2019) applied a clustering analysis and identified three different synoptic states of the Angola low: close to its seasonal climatology with slight zonal displacements, anomalously weak, and anomalously strong with meridional displacements. At the interannual time scale, the study by Crétat et al. (2019) confirms an association between the anomalously weak Angola low and El Niño and the southward phases of the Angola low and La Niña, as suggested by some previous studies (e.g., Cook 2000; Reason and Jagadheesha 2005), but also highlights that exceptions to this paradigm (e.g., 1997/98) due to additional large-scale coupled modes of variability. The recent study of Howard and Washington (2018), based on a distinction between dry heat and tropical states of the Angola low, supports the idea that the Angola low features considerable variability independent of ENSO during its tropical phase (i.e., from December to March), but what drives this variability remains unknown.

In their observational study, Lyon and Mason (2007) identified a stationary wave train originating over the extratropical South Atlantic as the main cause of the enhanced Angola low in January-March 1998. Lyon and 
TABLE 1. Description of model simulations used in this study.

\begin{tabular}{|c|c|c|c|}
\hline Experiment & Years & Ensemble members & Radiative forcing \\
\hline LONG_FLOR-FA & $1-3500$ & 1 & Atmospheric composition fixed at 1860 preindustrial level \\
\hline ALLFORC_FLOR-FA & $1861-2100$ & 5 & $\begin{array}{l}\text { Observational estimates of changes in greenhouse gases, } \\
\text { anthropogenic aerosols (direct effect only), ozone, land } \\
\text { use, solar irradiance and volcanic eruptions for } 1861- \\
\text { 2005; for the period after } 2005 \text {, the IPCC RCP } 4.5 \text { forcing } \\
\text { scenario is used. }\end{array}$ \\
\hline FLOR_fixedSST & $1-1001$ & 1 & $\begin{array}{l}\text { Prescribed monthly varying climatological SSTs, obtained } \\
\text { from the average of the last } 900 \text { yr of LONG_FLOR-FA. } \\
\text { Atmospheric composition fixed at preindustrial level } \\
\text { (1860). }\end{array}$ \\
\hline
\end{tabular}

Mason (2009) analyzed atmospheric general circulation models forced with SSTs observed during winter 1997/ 98, and seasonal forecasts from coupled global models for the same period. None of these numerical simulations was able to reproduce the stationary wave train. This led the authors to conjecture that extratropical atmospheric variability may have a key role in determining the seasonal features of the Angola low.

The scarcity of atmospheric data over the SA region and the relatively short duration of the most accurate and reliable reanalysis products, typically dating back to the end of the 1970s, do not presently allow us to have a full understanding of what controls the interannual variability of the Angola low. Here we will focus on this subject, seeking to address the following questions:

- To what degree is the Angola low interannual variability dependent on ENSO and other coupled atmosphereocean modes of natural variability?

- To what degree is the Angola low the main mechanism at play in the modulation of regional ENSO effects?

- To what degree is the Angola low interannual variability determined by SST anomalies, land memory effects and atmospheric internal variability?

To address these questions, we use both long-term coupled and fixed-SSTs numerical experiments (Table 1) performed with the coupled Forecast-Oriented Low Ocean Resolution (FLOR) model (Vecchi et al. 2014). FLOR is a coupled global climate model (GCM) with a 50-km horizontal resolution in the land-atmosphere components. As a model with a realistic representation of summertime SA rainfall and of the remote modes of variability affecting SA hydroclimate (in particular El Niño, see section 2c), FLOR is a novel source of insight to study SA climate. By providing thousands of simulated years featuring wet and drought conditions, FLOR provides a rare opportunity to answer these questions and to investigate the factors influencing the Angola low interannual variability.

The paper is structured as follows: in section 2 we describe the model experiments, the observations used for validation and the climatological indices to describe the Angola low; in section 3 we discuss the role of the anomalous states of the Angola low in El Niño years when atypical precipitation anomalies are realized; and section 4 investigates the local and remote drivers of anomalous states of the Angola low. Finally, in section 5 a discussion and summary of the main results is provided.

\section{Data and methods}

\section{a. Model and observational data}

We use a 3500-yr run (LONG_FLOR-FA, Table 1) with atmospheric radiative forcing (i.e., greenhouse gases, aerosols, and ozone, etc.) and land use fixed at preindustrial 1860 levels. LONG_FLOR-FA was obtained from the FLOR model (Vecchi et al. 2014), developed at the National Oceanic and Atmospheric Administration Geophysical Fluid Dynamics Laboratory (GFDL). The atmosphere and land components of FLOR are taken from the high-resolution GFDL Coupled Model version 2.5 (CM2.5; Delworth et al. 2012) with a horizontal resolution of approximately $50 \mathrm{~km} \times$ $50 \mathrm{~km}$. In contrast to CM2.5, which has an ocean component with horizontal spacing of about $0.25^{\circ}$, the ocean component of FLOR features a horizontal grid spacing of $1^{\circ}$. Both FLOR and CM2.5 have been successfully used to study regional hydroclimatic variability and change (e.g., Delworth and Zeng 2014; Delworth et al. 2016; Zhang et al. 2016; Zhang and Delworth 2018; Pascale et al. 2016; Barcikowska et al. 2018), particularly in regions featuring sharp topographic gradients (e.g., Kapnick et al. 2014; Pascale et al. 2017). FLOR provides skillful seasonal prediction for North America temperature and precipitation (Jia et al. 2015) and winter snowpack (Kapnick et al. 2018), extratropical storm activity (Yang et al. 2015) and tropical cyclone activity (Vecchi et al. 2014), and it is one of the GFDL's operational seasonal forecasts models in the North American Multimodel Ensemble (Kirtman et al. 2014). 
In addition to the coupled run, a 1000-yr run with prescribed climatological monthly SSTs (FLOR_fixedSST, Table 1) is also performed to isolate the influence of internal atmospheric dynamics upon the Angola low interannual variability, by removing the influence of coupled atmosphere-ocean modes.

All coupled simulations used in this study are obtained from the flux-adjusted version of FLOR (FLOR-FA, Table 1), in which climatological adjustments are made to surface fluxes of momentum, enthalpy and freshwater in order to bring the model ocean surface climatology closer to the observed 1979-2012 climatology. Applying the same adjustment correction for such a long run relies on the underlying assumption that the emergent error in the SST climatology remains constant in time. By substantially decreasing SST biases, flux adjustment considerably reduces the FLOR excessive spectral variance at periods of 2-3 years, thus improving the simulation of El Niño (Vecchi et al. 2014). Qualitatively similar results and conclusions are obtained with and without flux adjustment. However, in FLOR El Niño events are too strong and frequent (Vecchi et al. 2014; Wittenberg et al. 2018), thus exaggerating interannual variability of SA summer rainfall. Furthermore, the ENSO pattern over SA is abnormally shifted westward as in most of CMIP5 models (Dieppois et al. 2015), an error that is largely removed in FLOR-FA by reducing SST biases.

To analyze the observed summertime rainfall over SA, we use the Global Precipitation Climatology Centre, version 6 (GPCC v6) dataset (Schneider et al. 2014), based on statistically interpolated in situ rain measurements covering all land areas $\left(0.5^{\circ} \times 0.5^{\circ}\right.$ horizontal resolution) for the period 1901-2010 at monthly temporal resolution. Let us note that even in such dataset, precipitation uncertainty may be high as few in situ measurements go into the GPCC dataset in tropical regions of SA over the last 30 years. The impact of SST anomalies are assessed through the Extended Reconstructed Sea Surface Temperature dataset, version 5 (ERSST_v5; Huang et al.2017), which is a global monthly SST analysis from 1854 to the present, of which we use the 1901-2010 period to match the GPCC monthly precipitation dataset. GPCC and ERSST_v5 are available online at the NOAA/Physical Science Division Climate and Weather data website www.esrl.noaa.gov/psd/data/. Monthly means of geopotential height, wind, velocity potential and vorticity are compared to those from the European Centre for Medium-Range Weather Forecasts interim reanalysis product (ERA-Interim, hereafter ERA-I; Dee et al. 2011; Berrisford et al. 2011a, b). There are some substantial differences between reanalyses in terms of southern African circulation (Zhang et al. 2013). To have an idea of the uncertainty in the observed Angola low circulation, we also use another reanalysis product, MERRA (Rienecker et al. 2011). FLOR-FA's behavior is intermediate between the two reanalyses (Fig. S1 in the online supplemental material). The model is evaluated using the ALLFORC_FLOR-FA 5-member ensemble mean (Table 1). The five ALLFORC_FLOR-FA ensemble members have different initializations but are otherwise driven by identical observed changing radiative forcing over the historical period 1860-2005 (Zhang et al. 2016). After 2005, RCP4.5 forcing is applied. We consider years 1901-2010 for comparison with SSTs (ERSST_v5) and precipitation (GPCC), and years 1979-2014 for comparison with atmospheric dynamic fields (ERA-I, MERRA).

\section{b. Methodological approach}

The interannual variability of summer rainfall over subtropical SA is examined through the summer rainfall index (SRI; Dieppois et al. 2016). The SRI is here defined as the area-averaged rainfall over all grid points south of $20^{\circ} \mathrm{S}$ over Africa where November-March (NDJFM) rainfall amount contributes to at least $60 \%$ of total annual amount (Fig. 1a). To investigate summertime rainfall over the tropical part of the SA domain, we similarly define SRI 2 for the region between $10^{\circ}-20^{\circ} \mathrm{S}$.

The ENSO signal is described through the standard Niño-3.4 SST index (referred to as simply Niño-3.4 in the following), defined as the area-averaged SSTs over centraleastern Pacific $5^{\circ} \mathrm{N}-5^{\circ} \mathrm{S}, 170^{\circ}-120^{\circ} \mathrm{W}$ (e.g., Trenberth 1997). El Niño (La Niña) years are defined as those for which NDJF Niño-3.4 anomalies are larger (smaller) than $0.5 \mathrm{~K}(-0.5 \mathrm{~K})$. All remaining years are defined as ENSO neutral. Niño-3 $\left(5^{\circ} \mathrm{N}-5^{\circ} \mathrm{S}, 150^{\circ}-90^{\circ} \mathrm{W}\right)$ and Niño- $4\left(5^{\circ} \mathrm{N}-5^{\circ} \mathrm{S}, 160^{\circ} \mathrm{E}-150^{\circ} \mathrm{W}\right)$ indices are also calculated to better characterize different ENSO flavors (central vs eastern Pacific; e.g., Capotondi et al. 2015). The SIOD index (Behera and Yamagata 2001) is defined as the area-averaged SSTs over $37^{\circ} \mathrm{N}-27^{\circ} \mathrm{S}, 55^{\circ}-65^{\circ} \mathrm{E}$ minus area-averaged SSTs over $28^{\circ} \mathrm{N}-18^{\circ} \mathrm{S}, 90^{\circ}-100^{\circ} \mathrm{W}$. A negative (positive) SIOD is defined when the SIOD index is smaller (larger) than minus one standard deviation (plus one standard deviation). We also tested the influence of the Indian Ocean dipole as defined in Saji et al. (1999) and found no significant relationship with subtropical SA rainfall and the Angola low variability, in agreement with previous studies (e.g., Marchant et al. 2007; Hoell et al. 2017): this mode is therefore not discussed hereafter.

As in Crétat et al. (2019), we describe the Angola low through the 700-hPa relative vorticity. In particular, we define as a proxy for the strength of the Angola low cyclonic circulation the minimum of the vertical component of the $700-\mathrm{hPa}$ relative vorticity within $8^{\circ}-25^{\circ} \mathrm{S}$, 

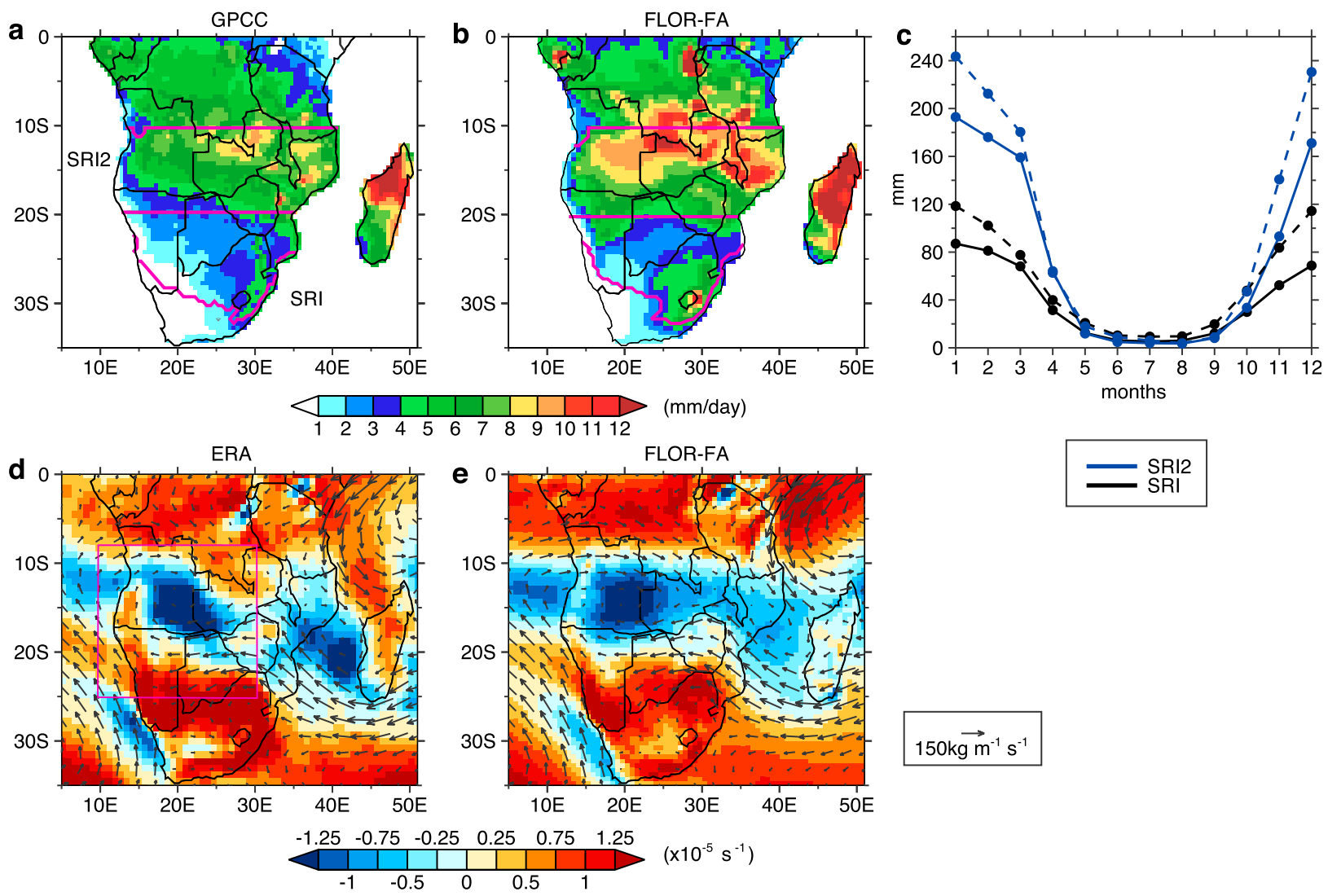

FIG. 1. Climatological DJF precipitation $\left(\mathrm{mm} \mathrm{day}^{-1}\right.$ ) during 1901-2010 in (a) GPCC and (b) FLOR-FA (ALLFORC_FLOR-FA, ensemble mean). Magenta lines delineate the area between $10^{\circ}$ and $20^{\circ} \mathrm{S}$, and the region south of $20^{\circ} \mathrm{S}$ for which NDJFM rainfall accounts for more than $60 \%$ of annual totals, which are used for the calculation of SRI2 and SRI. (c) Annual cycles of SRI (black) and SRI2 (blue) in GPCC and FLOR-FA (dashed line). (d) Climatological DJF 700-hPa relative vorticity (vertical component, $\times 10^{5} \mathrm{~s}^{-1}$, color shading) and vertically integrated (from surface to $700 \mathrm{hPa}$ ) moisture flux during 1979-2010 (DJF) in ERA Interim and (e) in FLOR-FA. The magenta rectangle denotes the region over which we seek for the 700-hPa relative vorticity minimum.

$10^{\circ}-30^{\circ} \mathrm{E}$ (Fig. 1d), and its coordinates (longitude, latitude) as a proxy for the position. We choose the $700-\mathrm{hPa}$ relative vorticity -instead of the more intuitive $850-\mathrm{hPa}$ geopotential height-because this variable discriminates well the tropical low, featuring large negative values (Fig. 1d), from the dry heat low, which instead features relative vorticity null at $700 \mathrm{hPa}$ (Fig. 3 in Howard and Washington 2018). In addition to that, many high-elevation surface grid points in FLOR-FA are above the 850 -hPa geopotential height in the prescribed rectangle. While the modes shown by the Angola low are much more multifaceted (Crétat et al. 2019), here we choose a minimal set of indices consisting of v700 and LATv700 (Table 2). LATv700 (v700) is the latitude (minimum) of the $700-\mathrm{hPa}$ relative vorticity minimum within $\left(8^{\circ}-25^{\circ} \mathrm{S}, 10^{\circ}-30^{\circ} \mathrm{E}\right)$. This choice is motivated by the fact that the strength of the cyclonic circulation and the meridional location of the Angola low are, at first order, the most important factors affecting SA summer rainfall. All indices in Table 2 are derived from monthly means. The characteristics of "north," "south," and "intermediate" states of the Angola low are obtained by compositing JF fields of interest (precipitation, water vapor fluxes, geopotential heights) for all years during which JF LATv700 is larger than its lower tercile, smaller than its upper tercile, and between its lower and upper tercile, respectively. "Strong" and "weak" states of the Angola low are similarly defined in terms of v700.

To determine the relationship between the climatological indices defined in Table 2, we use the amplitude squared coherence and its phase from cross spectral analysis (e.g., von Storch and Zwiers 2003). The amplitude squared coherence $C_{x y}(f)$ :

$$
C_{x y}(f)=\frac{\left|P_{x y}(f)\right|^{2}}{P_{x x}(f) P_{y y}(f)}
$$

measure the coherence between two time series $x$ and $y$ (e.g., $x=$ SRI and $y=$ Niño-3.4), in which $P_{x x}(f)$ and 
TABLE 2. List of symbols for the climatological indices introduced in section $2 b$.

\begin{tabular}{lc}
\hline \hline Index & Definition \\
\hline Niño-3.4 & Area-averaged SSTs over central-eastern Pacific \\
& $\left(5^{\circ} \mathrm{N}-5^{\circ} \mathrm{S}, 170^{\circ}-120^{\circ} \mathrm{W}\right)$ \\
SIOD & Area-averaged SSTs over $\left(37^{\circ} \mathrm{N}-27^{\circ} \mathrm{S}, 55^{\circ}-65^{\circ} \mathrm{W}\right)$ \\
& minus area-averaged SSTs over $\left(28^{\circ} \mathrm{N}-18^{\circ} \mathrm{S}\right.$, \\
& $\left.90^{\circ}-100^{\circ} \mathrm{W}\right)$ \\
SRI & Area-averaged monthly precipitation over land grid \\
& points south of $20^{\circ} \mathrm{S}$ for which NDJFM rainfall \\
& accounts for more than $60 \%$ of annual totals \\
SRI2 & Area-averaged monthly precipitation over land grid \\
& points between $10^{\circ}-20^{\circ} \mathrm{S}$ for which NDJFM rain- \\
& fall accounts for more than $60 \%$ of annual totals \\
LATv700 & Latitude of the $700-\mathrm{hPa}$ relative vorticity minimum \\
& within $\left(8^{\circ}-25^{\circ} \mathrm{S}, 10^{\circ}-30^{\circ} \mathrm{E}\right)$ \\
v700 & Minimum value of the 700 -hPa relative vorticity \\
& minimum within $\left(8^{\circ}-25^{\circ} \mathrm{S}, 10^{\circ}-30^{\circ} \mathrm{E}\right)$ \\
$\Delta z_{200}$ & Difference of area-averaged 200 -hPa stationary \\
& wave geopotential height between regions 1 and \\
& 2 (Fig. 13$)$ \\
\hline
\end{tabular}

$P_{y y}(f)$ are the power spectral density of $x$ and $y$ and $P_{x y}(f)$ is the cross-power spectrum spectral density. The squared coherence $C_{x y}$ is a function of frequency $f$ and ranges between 0 and 1, indicating how well $x$ correlate to $y$ at each frequency. The phase of $C_{x y}(f)$

$$
\Theta_{x y}=\arg \left(C_{x y}\right)
$$

provides information about the phase relationship of $x$ and $y$ (e.g., $\Theta_{x y} \approx 0$ for positively correlated time series, $\Theta_{x y} \approx \pi$ for negatively correlated time series).

Associations between ENSO and SA rainfall are evaluated through standard linear correlation and regression techniques. To evaluate the dependence of SRI from other SST modes independent from ENSO, we calculate partial correlations. To compute partial correlations, residuals are calculated after regressing both SST and SRI on Niño-3.4, then the correlation between these residuals is worked out. Surface conditions associated with different states of the Angola low are evaluated by generating composites of SST anomalies. To identify possible modes of extratropical atmospheric variability in the Southern Hemisphere, stationary wave patterns (e.g., Nigam and DeWeaver 2003) are investigated by examining composites of anomalies in 200and $700-\mathrm{hPa}$ geopotential height for which the zonal means have been subtracted.

\section{c. Southern Africa summer rainfall in FLOR-FA}

FLOR-FA qualitatively captures the spatial pattern of summer SA rainfall as well as the annual cycle (Figs. 1a-c). Precipitation amounts are generally overestimated by approximately $20 \%$, a minor bias relative to models from phase 5 of the Coupled Model Intercomparison Project (CMIP5; Taylor et al. 2012), which typically substantially overestimate precipitation over SA (Fig. S2). Austral summertime circulation with its regions of upper-level divergence indicating strong vertical motion and deep convection is also generally well captured (Figs. S3 and S4). The Angola low, highlighted by the $700-\mathrm{hPa}$ vertical relative vorticity and surface-700-hPa vertically integrated moisture fluxes, has its climatological center over southeastern Angola (Fig. 1d) and it appears realistically simulated in FLOR-FA as compared to ERA-I and MERRA reanalysis (Fig. S1).

We evaluate the model's skill to represent the relationship between SA summer rainfall and global SST anomalies by showing the correlation map between SST anomalies and the mean summer rains over subtropical SA (i.e., SRI) for both observations and model (Fig. 2). FLOR-FA captures the effect of El Niño on SA summer rainfall, as evident from the negative correlations between SRI and the tropical Pacific SSTs (Fig. 2b) and the statistically significant negative regression values of rainfall anomalies onto the Niño-3.4 SST index over subtropical SA (Fig. 3a). The positive height anomaly centered at approximately $60^{\circ} \mathrm{S}, 120^{\circ} \mathrm{W}$ and flanked by negative anomalies to its west and east, known as the Pacific-South American (PSA) pattern (Mo and Paegle 2001) (Fig. 3b), and the enhanced upper-level convergence near Indonesia, both typically associated with El Niño, are also realistically reproduced (Fig. 3c). In the representation of the teleconnection between ENSO and SA rainfall, FLOR-FA outperforms many of the currently used GCMs (e.g., CMIP5), which struggle to reproduce the correct ENSO-SA teleconnection pattern as they abnormally shift westward the typical ENSO patterns over the southern Indian Ocean [Fig. 9 of Dieppois et al. (2015)].

FLOR-FA also captures the negative correlation between the SRI and the Indian Ocean SSTs (Fig. 2). The variability of SA rainfall is statistically related to both Pacific and Indian Oceans, although the SST variability in the two oceans are not fully independent (e.g., Goddard and Graham 1999). The negative correlation with the tropical Indian Ocean SSTs is substantially weakened after removing the ENSO influence through partial correlations (Fig. S5). FLOR-FA captures relatively well the positive correlation between the SRI and the SIOD, identified by the dipolar pattern to the east of the SA region and whose variability is mostly independent from ENSO. The association with a dipolar mode in the subtropical southern Atlantic_-suggested to be closely interrelated, with the SIOD (Fauchereau et al. 2009) -is also captured by FLOR-FA. 

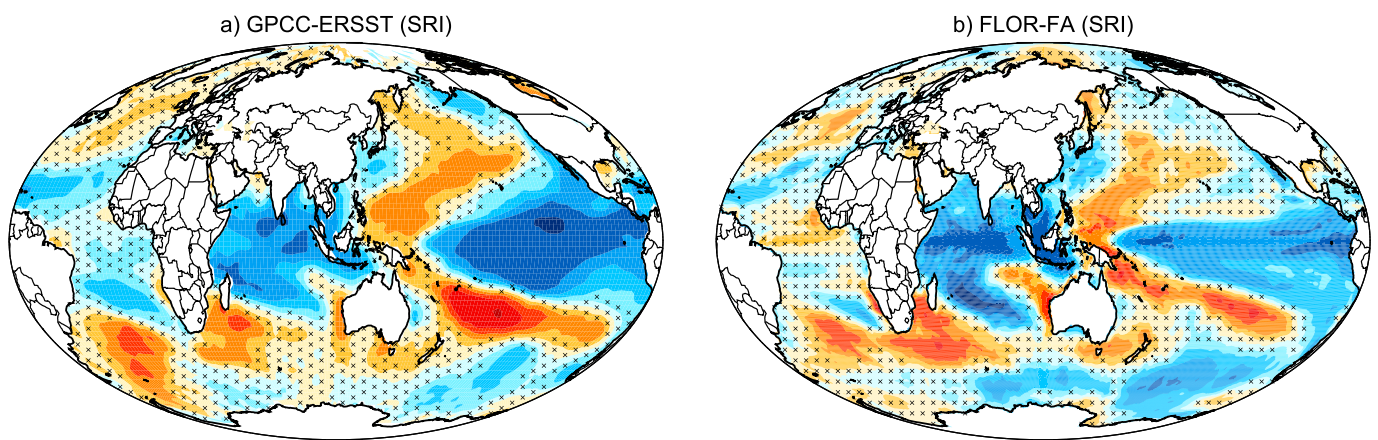

$-0.5-0.4-0.3-0.2-0.1 \quad 0 \quad 0.10 .20 .30 .40 .5$

FIG. 2. Correlation coefficient between NDJFM SRI and NDJFM SST anomaly during 1901-2010 in (a) observations (GPCC, ERSST_v5) and (b) FLOR-FA historical run (ensemble mean). Regions that are not statistically significant at the $5 \%$ level on the basis of a $t$ test are stippled.

Overall, evidence shown in Figs. 1-3 and in Figs. S1S5 demonstrate the good skill of FLOR-FA to simulate both the SA summer climate and the ENSO-SA teleconnection. This is relatively rare among GCMs. For instance, CMIP5 GCMs severely overestimate precipitation (Fig. S2; Lazenby et al. 2016; Munday and Washington 2017, 2018) and fail to capture the right pattern of the ENSO-SA rainfall teleconnection a) GPCC

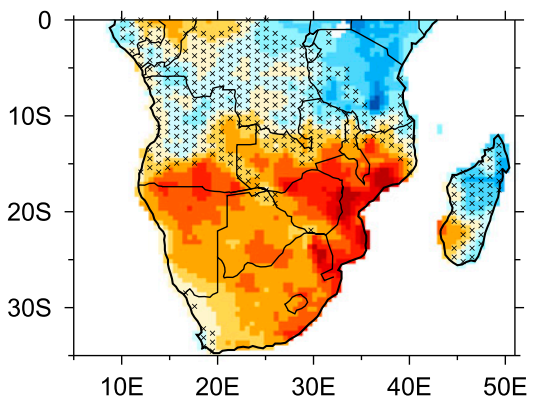

d) FLOR-FA

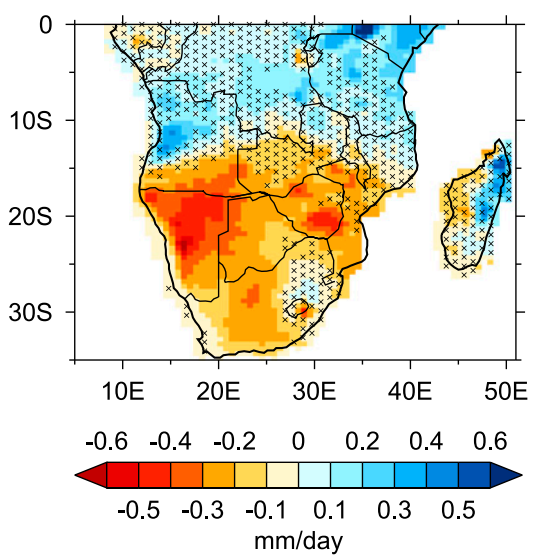

b) ERA-I

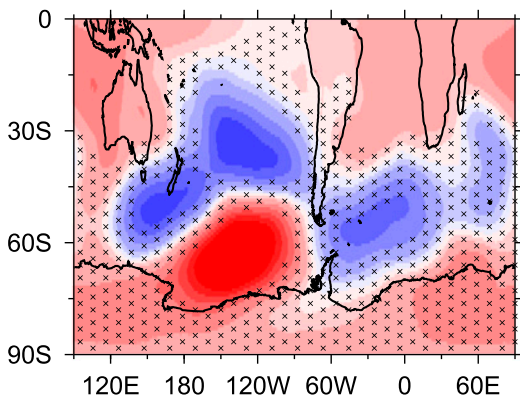

e) FLOR-FA

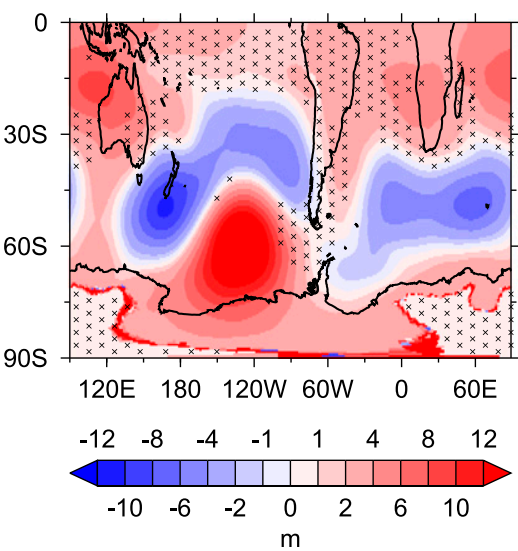

c) ERA-I

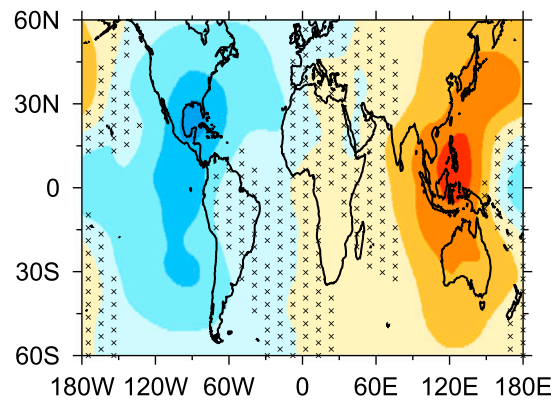

f) FLOR-FA

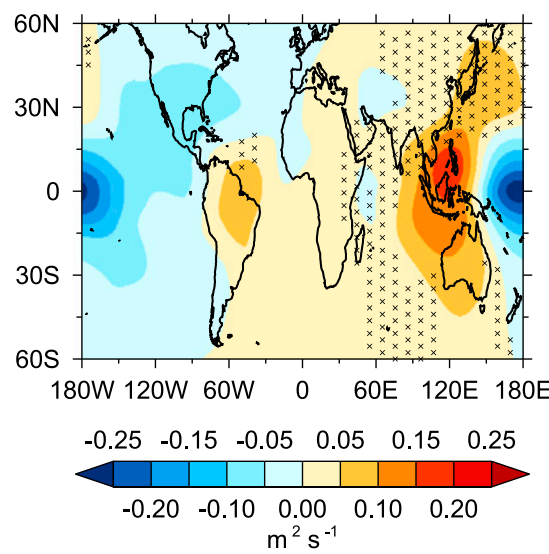

FIG. 3. Linear regression of NDJFM (a) precipitation, (b) 700-hPa geopotential height, and (c) 200-hPa velocity potential anomalies on the standardized Niño-3.4 index for observations/reanalyses (GPCC, ERSST_v5, ERA Interim). (d)-(f) As in (a)-(c), but for the ALLFORC_FLOR-FA runs (ensemble mean, Table 1). Regions that are not statistically significant at the $5 \%$ level on the basis of a $t$ test are stippled. 
a $\quad$ GPCC-ERSST (1901-2010)

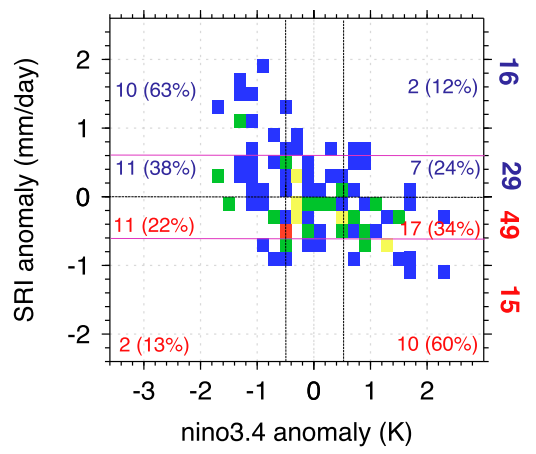

b FLOR-FA (1901-2010)

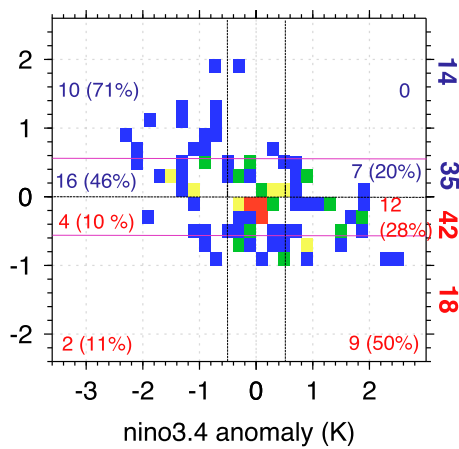

c

FLOR-FA (3500 years)

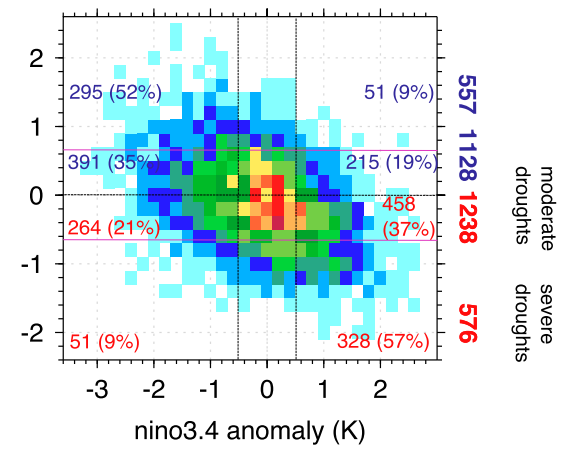

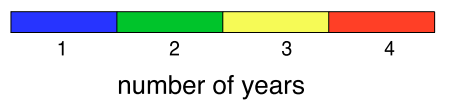

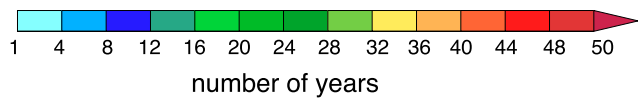

FIG. 4. Two-dimensional histogram of NDJFM SRI and Niño-3.4 index anomalies (bin: $0.2 \mathrm{~K} \times 0.2 \mathrm{~mm}^{-1}$ day $^{-1}$ ) for (a) observations (GPCC and ERSST_v5, 1901-2010), (b) FLOR-FA historical run (1901-2010, one ensemble member), and (c) FLOR-FA preindustrial control run (3500 years). Magenta horizontal lines denote \pm standard deviation $(\sigma)$ in SRI anomalies; vertical black lines the $\pm 0.5 \mathrm{~K}$ Niño3.4 anomalies (El Niño/La Niña). The bold blue (red) numbers on the $y$ axis indicate the number of years for which SRI anomalies are larger than $\sigma$ and between 0 and $\sigma$ (SRI anomalies $<-\sigma$ and between 0 and $-\sigma$ ). For each of those, the number and percentage of such years occurring during El Niño and La Niña are also reported [e.g., of all the 16 very wet years for which SRI anomalies are larger than one standard deviation, the $12 \%$ (i.e., 2, were El Niño years)].

(Dieppois et al. 2015). This justifies the use of FLOR-FA as a surrogate of the real world to investigate the drivers of Angola low interannual variability.

\section{The role of the Angola low during nonstandard ENSO years}

A total of $36 \mathrm{El}$ Niño years and $34 \mathrm{La}$ Niña years are identified over the 1901-2010 period in the ERSST_v5 dataset. Observations show that Niño-3.4 and SRI anomalies feature a negative correlation of about -0.45 . The negative correlation between Niño-3.4 and SRI anomalies is evident from the elongated shape of the two-dimensional distribution in Fig. 4a, which shows how frequently a joint value of SRI and Niño-3.4 has occurred during the 1901-2010 period. Of all El Niño (La Niña) years, 75\% (58\%) are characterized by negative (positive) SRI anomalies. A total of 15 (16) years with particularly dry (wet) conditions [i.e., with SRI anomalies smaller (larger) than minus one standard deviation (plus one standard deviation)] are identified over the same period, $66 \%$ (62\%) of which occur during El Niño (La Niña). Just for the sake of visual comparison and even though years in the model have no particular correspondence with the real world, one member of the ALLFORC_FLOR-FA ensemble (Table 1) is shown over the same period (Fig. 4b). The range of the SRI and Niño-3.4 is similar in both observations and FLOR-FA, though FLOR-FA tends to slightly underestimate the negative correlation between SRI and Niño-3.4 ( $\approx-0.37)$. Many gaps in the SRI-Niño3.4 anomaly plane are evident in the two-dimensional histograms in Figs. 4a and 4b, as the 110-yr-long record cannot provide a complete view of the SRI-Niño-3.4 relationship. The 3500-yr FLOR-FA simulation (Fig. 4c) provides a relatively large number of nondry El Niño (266 out of 1052 years) and nonwet La Niña (315 out of 1001 years) instances during SA summer, allowing for a more robust characterization of the causes of nonstandard ENSO years.

Motivated by the growing evidence of the role played by the Angola low as a driver of SA summer rainfall (Cook et al. 2004; Reason and Jagadheesha 2005; Lyon and Mason 2007; Crétat et al. 2019; Howard and Washington 2018; Blamey et al. 2018), we investigate in the LONG_FLOR-FA run to what extent the meridional displacement and the strength of the AL determine dry/wet conditions during ENSO conditions. In general, when in a "south" state (Figs. 5a-c), the Angola low is characterized by a more active cyclonic circulation around its center (displaced approximately $3^{\circ}$ southward), more intense northwesterly moisture fluxes from Angola into subtropical SA, and stronger northerly moisture fluxes from the nearby Indian Ocean due to a weakening of the Mozambique Channel Trough. Widespread positive precipitation anomalies are present south of $20^{\circ} \mathrm{S}$. "Strong" states of the Angola low (Figs. 5d,e) are instead associated with stronger 
a) Southward displaced Angola Low

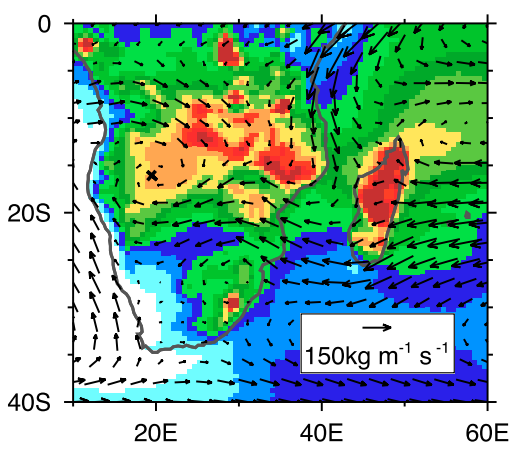

b) Northward displaced Angola Low

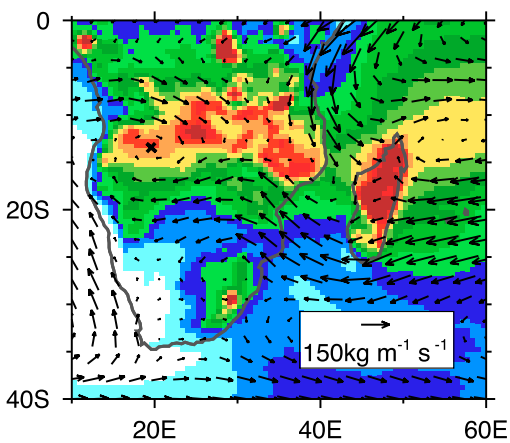

c)

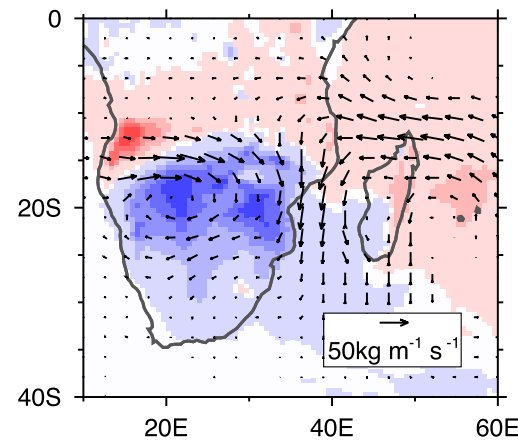

d)

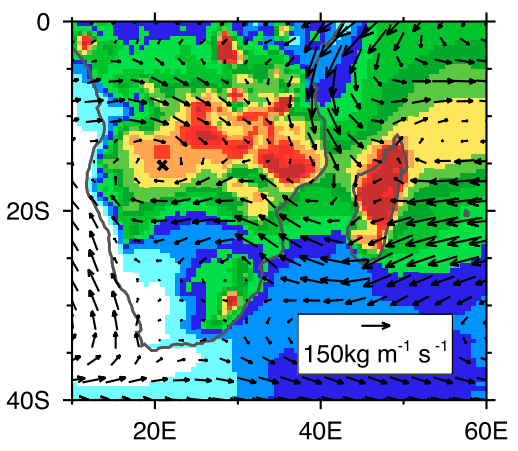

e)

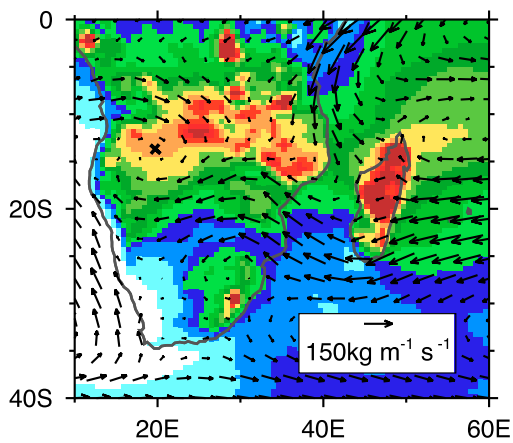

f)
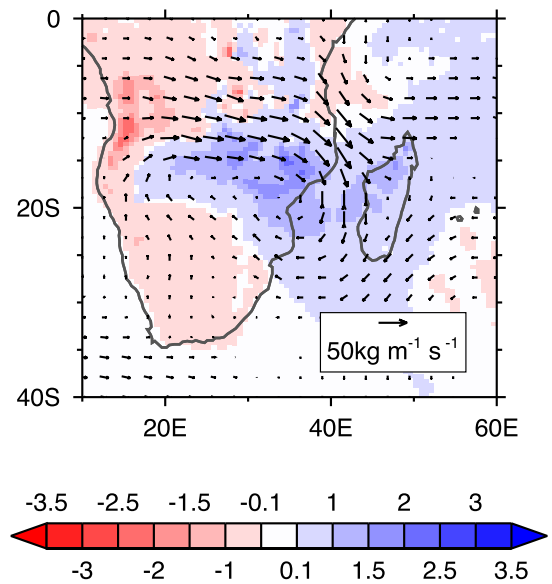

FIG. 5. January-February mean vertically integrated (from surface to $700 \mathrm{hPa}$ ) moisture flux (vectors) and precipitation (shading, $\mathrm{mm}_{\text {day }}{ }^{-1}$ ) for the composite of the (a) "south" states and, (b) "north" states of the Angola low, and (c) the difference between the two. (d)-(f) As in (a)-(c), but for "strong" and "weak" states of the Angola low. The black cross indicates the approximate position of the Angola low.

westerly moisture fluxes over tropical SA and increased precipitation in the area between Zambia and Madagascar, mostly north of $20^{\circ} \mathrm{S}$.

We create composites of dry/wet years for different remote SST forcing conditions: ENSO neutral years, El Niño years, and El Niño with negative SIOD years (El Niño/SIOD-). The El Niño/SIOD - composite is of interest since this state has been claimed to provide the most favorable conditions for extreme droughts over southern Africa (Hoell et al. 2017). For each of these composites, we quantify how frequently the Angola low is at certain latitude (Fig. 6). We differentiate the analyses for two periods, November-December and January-February, since the Angola low is typically less developed during early summer (Munday and Washington 2017). Histograms show that the mean monthly meridional position of the Angola low strongly controls the amount of rainfall over SA south of $20^{\circ} \mathrm{S}$ both in
November-December (Figs. 6a-c) and January-February (Figs. 6d-f). In particular, all wet composites are associated with a $700-\mathrm{hPa}$ vorticity minimum approximately $2^{\circ}-3^{\circ} \mathrm{S}$ south of its climatological position $\left(12^{\circ} \mathrm{S}\right.$ in November-December and $14^{\circ} \mathrm{S}$ in January-February), at about $15^{\circ} \mathrm{S}$ in November-December and $17^{\circ} \mathrm{S}$ in January-February. In contrast, the dry composites have an Angola low located at about $12^{\circ}$ and $13^{\circ} \mathrm{S}$ for the two periods, respectively.

From the histograms in Figs. 6d-f, the probability of an Angola low south of $17^{\circ} \mathrm{S}\left(15^{\circ} \mathrm{S}\right)$ in January-February is approximately $20 \%$ (42\%) during ENSO neutral conditions, $16 \%$ (35\%) during El Niño and 13\% (31\%) during El Niño/SIOD-. Therefore, an Angola low displaced to the south (e.g., LATv700 $<15^{\circ}$ S) can still occur nearly $35 \%$ (31\%) of the times during El Niño (El Niño/SIOD-) conditions. This suggests that ENSO and the SIOD have only a limited influence on the Angola 

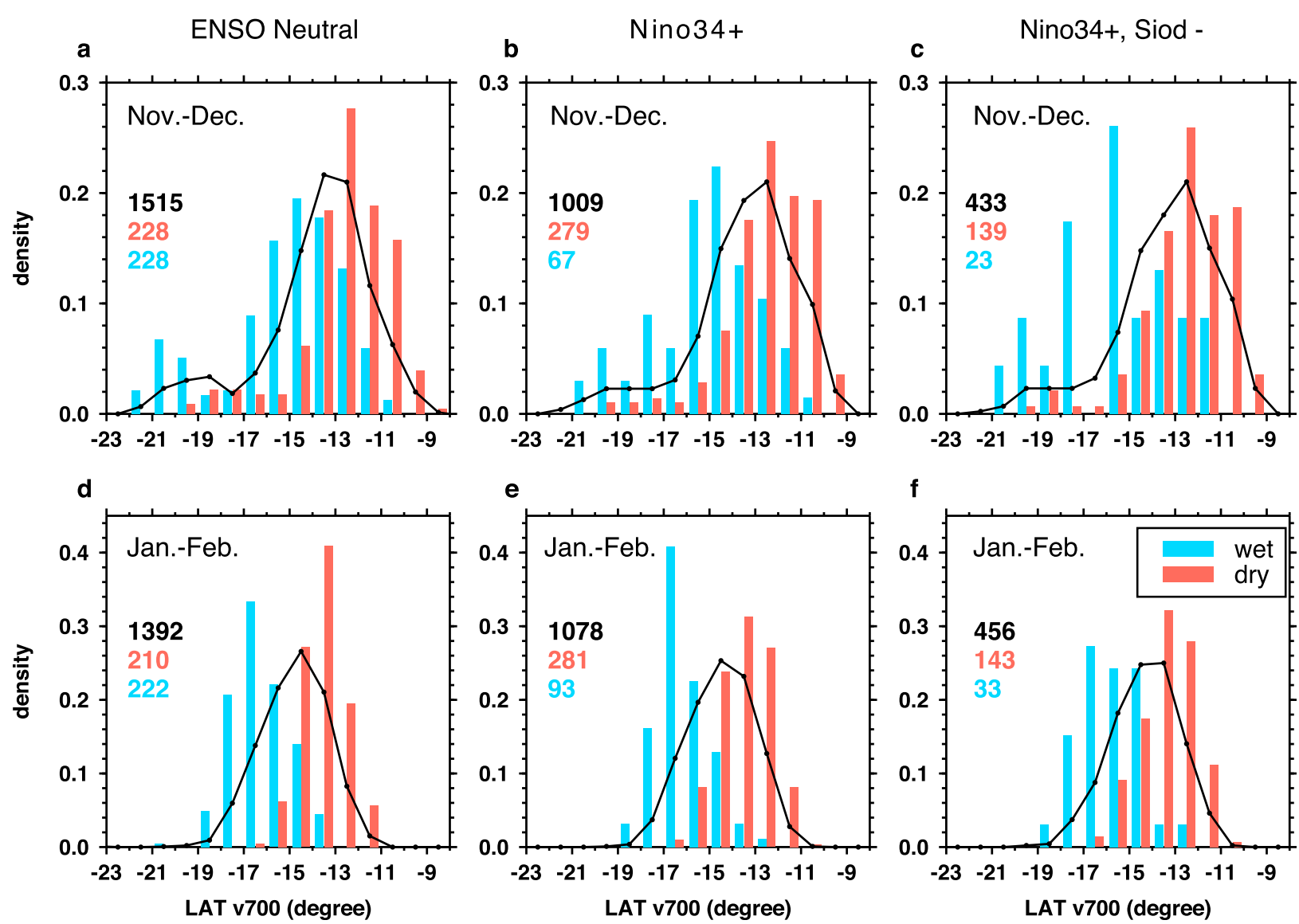

FIG. 6. Histograms (black line) of the mean November-December Angola low meridional position (LATv700) for (a) ENSO neutral years, (b) El Niño years (Niño-3.4 anomaly larger than 0.5 K), and (c) El Niño and negative SIOD years in the 3500-yr FLOR-FA control run. For each category, histogram of wet (SRI anomalies above one standard deviation) and dry (SRI anomalies below minus one standard deviation) years are also shown through color bars. Bin size is of $1^{\circ}$ as reported on the $x$ axis. Histograms for the wet and dry years (colored bars) are displaced slightly for clarity, but are otherwise estimated using the same bins as for the full case (black line). (d)-(f) As in (a)-(c), but for January-February means. Number of years for each category reported on each plot.

low, and other modes of variability must influence it, too. Similar conclusions can be drawn for the strength of the cyclonic circulation associated with the Angola low (Figs. S6 and S7), which affects seasonal rainfall only north of $20^{\circ} \mathrm{S}$ (i.e., SRI2).

\section{Controls of the Angola low interannual variability}

In the following we focus on the drivers of the interannual variability of the Angola low. We build composites of SRI and LATv700 anomalies for all the four possible combinations of the ENSO and SIOD phases (Fig. 7). While ENSO clearly modulates the SRI (statistical distribution shifted between El Niño and La Niña), the phase relationship of ENSO with SIOD is somewhat of lesser importance for the position of the Angola low. The distribution of LATv700 seems to be less affected by the different phases of ENSO and SIOD as compared to SRI. This reinforces the idea that the interannual variability of the Angola low can only be partially explained by ENSO. To investigate this further, we analyze the power spectra and cross spectra of January-February SRI, Niño-3.4, SIOD and LATv700 (Fig. 8). The SRI is characterized by significant variability at interannual and decadal time scales (a detailed time-dependent view is provided by the continuous wavelet power spectrum of the SRI in Fig. S8). The Niño-3.4 index does not have significant periodicities at time scales longer than 5 years (bottom left panel of Fig. 8), so it is unlikely it can explain the SRI decadal and interdecadal time variability. Notably, SIOD and LATv700 do feature significant variance at decadal (and longer) periods, suggesting that they might play a role at explaining decadal and multidecadal variability of SA summer rainfall (e.g., Dieppois et al. 2016). 

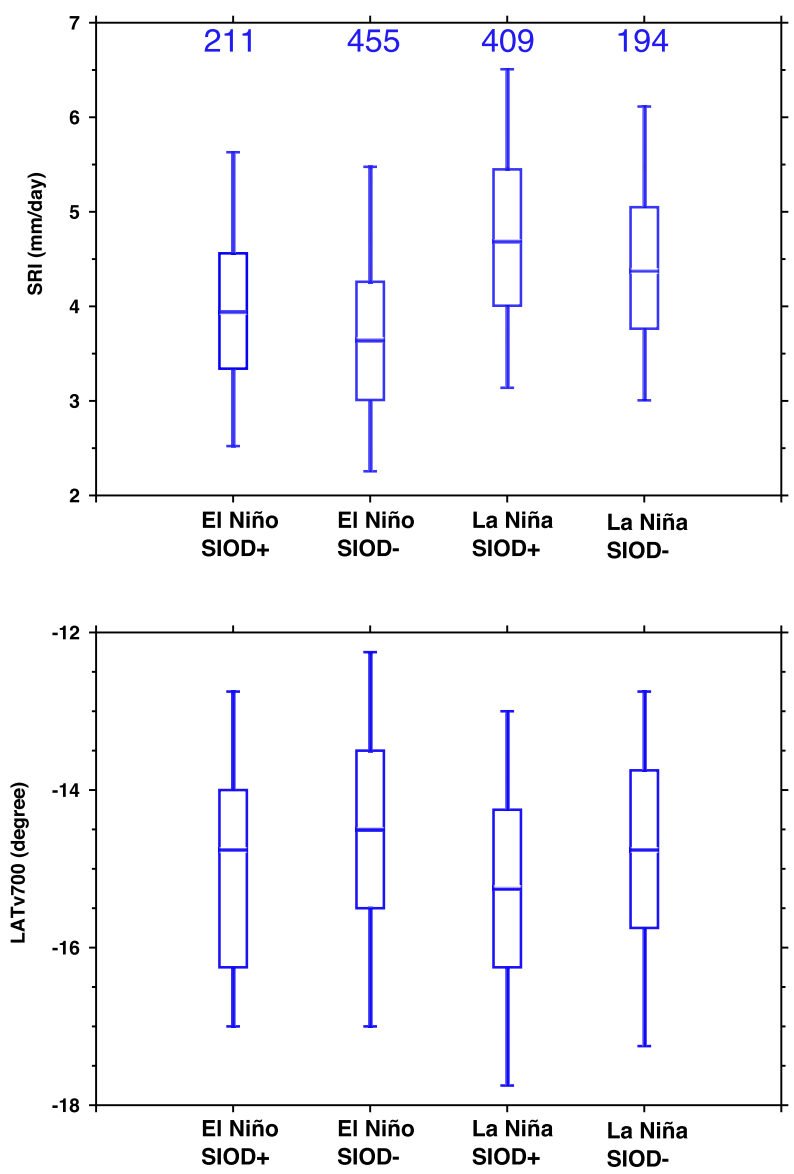

FIG. 7. Box-and-whisker plot (5th, 25th, 50th, 75th, 95th percentiles) of (top) JF SRI and (bottom) LATv700 for the four different ENSO and SIOD nonneutral composites. Blue numbers represent the number of instances (seasons) that go into each boxand-whisker.

Cross-spectral analysis shows that LATv700 and SRI feature a relatively high squared coherence and an opposite-phase $(\approx \pi)$ relationship (i.e., the larger the SRI anomalies, the farther south the Angola low) with values around $50 \%-60 \%$ at the interannual time scale ( $2-5$ years), $65 \%$ at the decadal time scale (10-20 years) and $60 \%$ at centennial time scales. LATv700 and Niño3.4 are in-phase and feature some significant coherence, though not large $(\approx 25 \%)$, at periods of approximately $2-10$ years, consistent with Fig. 7. Similar values $(\approx 20 \%)$ of squared coherence and opposite-phase relationship are observed between LATv700 and SIOD around 2-3and 10-20-yr periods. The modest values of squared coherence of LATv700 with Niño-3.4 and SIOD demonstrate that ENSO and the SIOD can only explain roughly $20 \%-25 \%$ of the variance of the Angola low meridional position. This implies that other drivers, not represented or not well captured by the indices in
Table 2, must be involved in the modulation of the Angola low.

\section{a. Role of atmosphere-ocean coupled modes}

We estimate the correlation between LATv700, v700, and SST anomalies in the LONG_FLOR-FA run (Fig. 9) to investigate the relationship of the Angola low position with atmosphere-ocean coupled modes which may be not well captured by the set of indices listed in Table 2. Regarding the ENSO-Angola low association, we see that both the Angola low latitudinal position and strength are not particularly correlated with SST anomalies in the central-eastern Pacific in November-December (Figs. 9a,b) and only moderately $(\leq 0.25)$ correlated in January-February (Figs. 9c,d). This is consistent with the spectral analysis in Fig. 8. In November-December, there is also a significant positive correlation (0.25) between the tropical Atlantic SSTs and v700 (Fig. 9b), with the positive correlation pattern narrowing along the Angolan and Namibian coast in January-February. These correlation patterns are suggestive of a decrease in the intensity of the Benguela upwelling system (Fennel 1999). A strengthening of the meridional equatorward winds due to a stronger Angola low could increase the upwelling system and thus lead to more negative SST anomalies. In such a case, the Atlantic SST anomalies would not be a forcing on the Angola low, but merely a consequence of the atmospheric changes. However, this goes beyond the scopes and possibilities of a correlation analysis. A stronger and significant negative correlation of approximately -0.3 exists in January-February between each of v700 and LATv700, and surface temperatures to the southwest of Madagascar and east of southern Africa (Figs. 9c,d). In the case of LATv700, the negative correlation coefficient is also associated with a positive correlation pattern to the northeast of it, thus forming a dipolar structure reminiscent of the SIOD but otherwise closer to the African coast. The sensitivity of the Angola low position to the proximity of SST anomalies to the African coast in the western subtropical Indian Ocean agrees with previous idealized modeling studies (Reason 2002).

Next, we explore if there exists any statistically significant differences in the global SST anomalies in relation with "north" and "south" states of the Angola low. Here we focus on the January-February because these are the summer months when the tropical Angola low is stronger and more clearly developed. Since we are particularly interested in the noncanonical years, we further subdivide each "north" and "south" composites into ENSO neutral, El Niño and El Niño/negative SIOD subcomposites (Fig. 10). An El Niño concomitant with a negative SIOD has been claimed to provide the most 

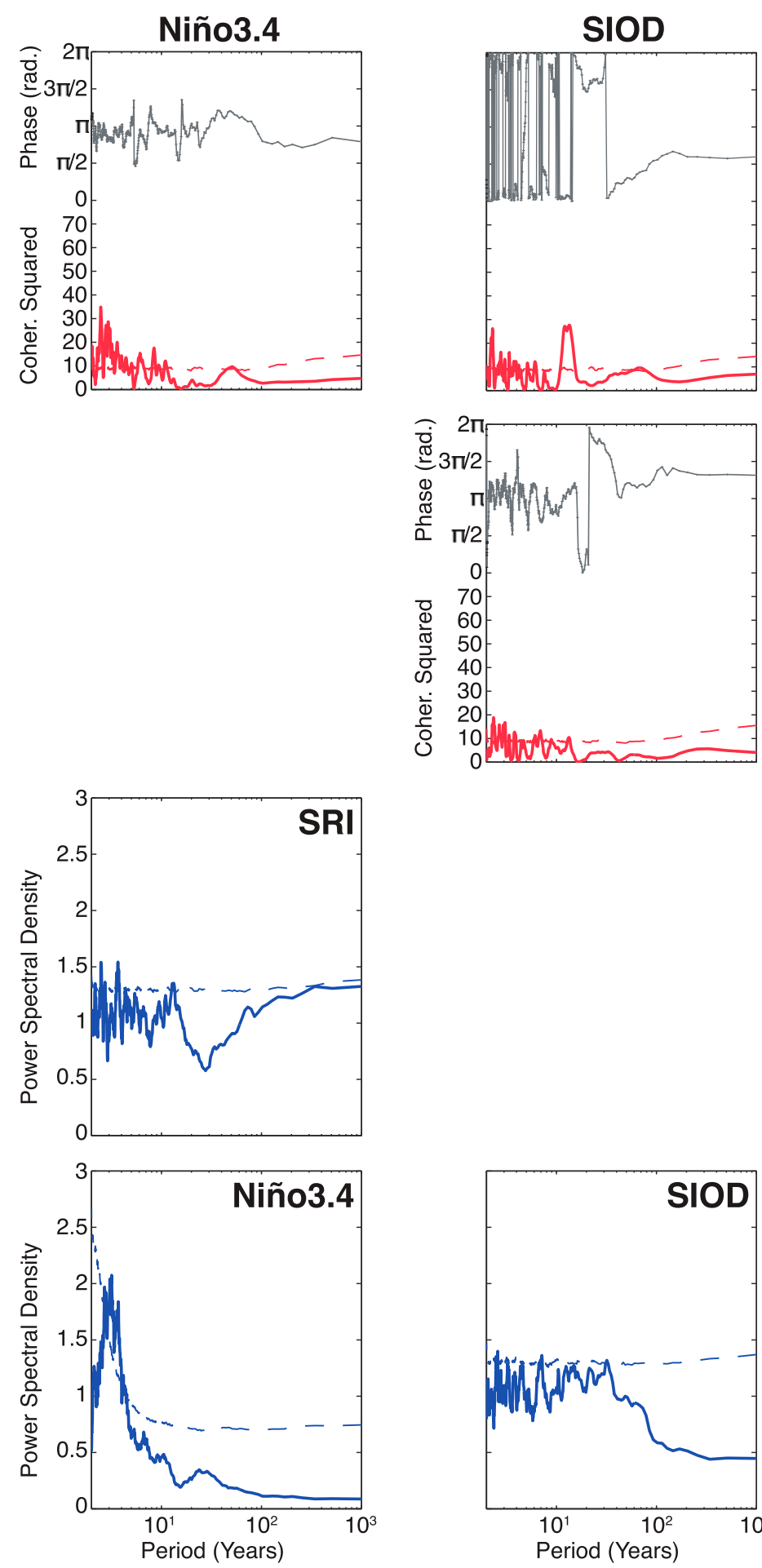

SIOD

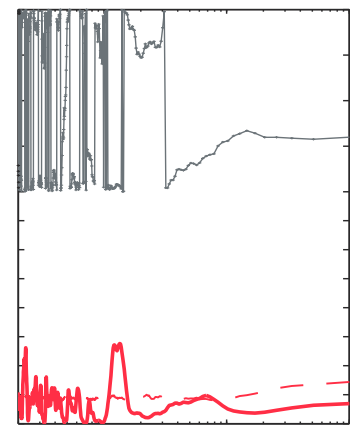

AL lat.
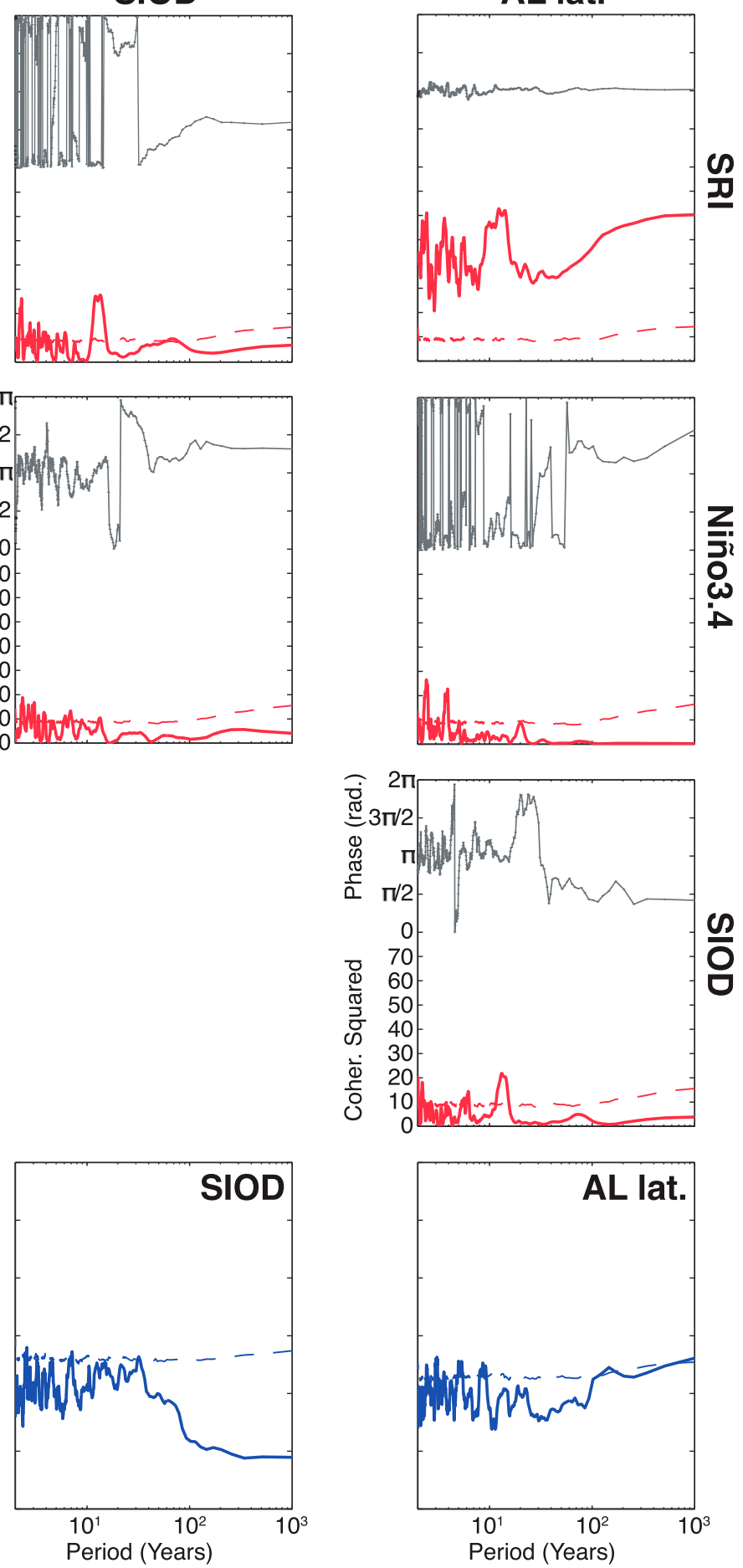

FIG. 8. Cross-spectrum matrix (top-right corner) and power spectra (bottom-left corner) of the SRI, Niño-3.4, SIOD, and LATv700 indices. All analyses are carried out on normalized data for the January-February 3500-yr period, with other months padded with zeros. Red lines denote square coherence [\%; Eq. (1)]. Gray solid lines with plus signs denote the phase relationship [Eq. (2)]. Blue solid lines denote the power spectrum. Dashed lines indicate the $95 \%$ level according to 1000 random time series obtained as permutations of the original time series, and having the same lag- 1 serial correlation. 
a) Correlation LATV700-SSTs (November-December)

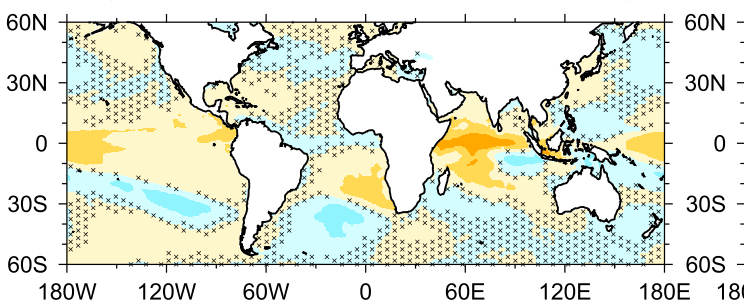

c) Correlation LATV700-SSTs (January-February) b) Correlation v700-SSTs (November-December)

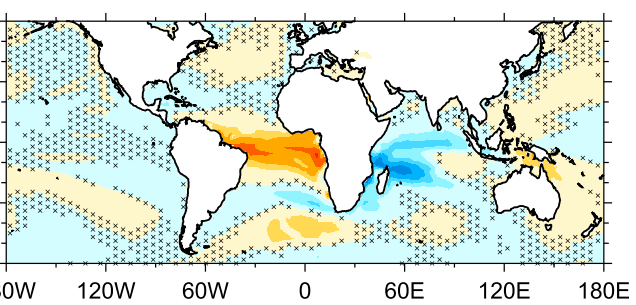

d) Correlation v700-SSTs (January-February)

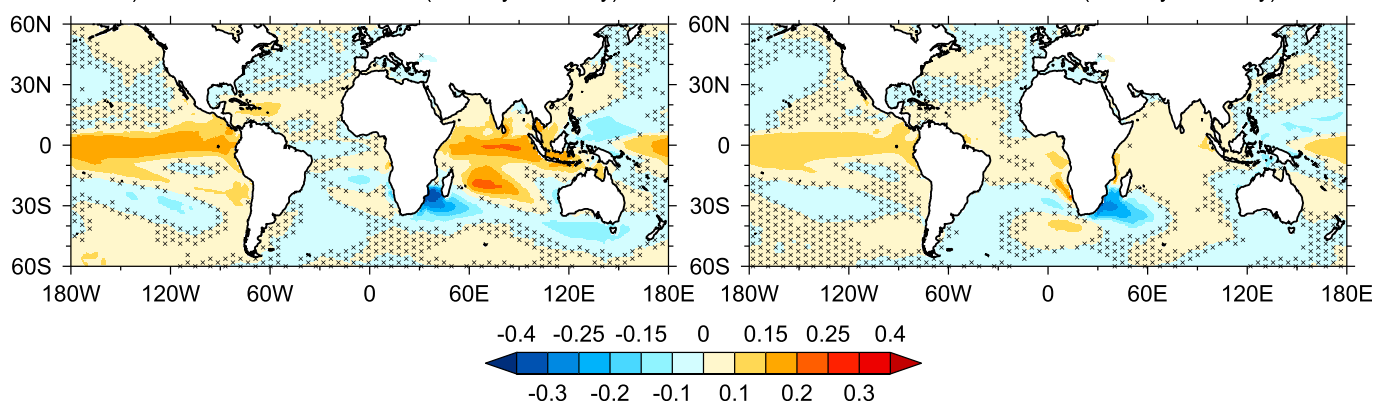

FIG. 9. Correlation coefficient between November-December SST anomalies and (a) November-December LATv700 and (b) November-December v700. (c),(d) As in (a),(b), but for the January-February period. Regions that are not statistically significant at the $5 \%$ level on the basis of a $t$ test are stippled. favorable conditions for extreme droughts over southern Africa (Hoell et al. 2017). Differences in SST anomalies between north and south states of the Angola low, for ENSO neutral, El Niño, and El Niño/SIOD- subcomposites, are not striking, although there are some noteworthy differences (Fig. 10). ENSO composites (Figs. 10b,e) do not feature appreciable SST anomaly differences in the Pacific Ocean, implying that ENSO a) ENSO NEUTRAL, AL north

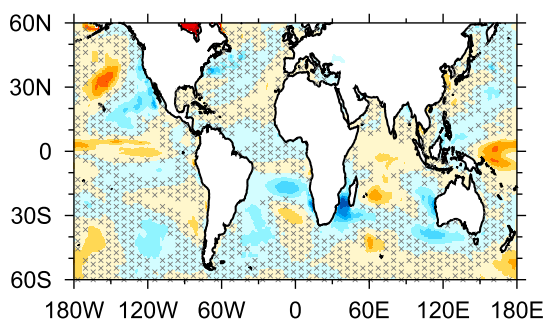

d) ENSO NEUTRAL, AL south
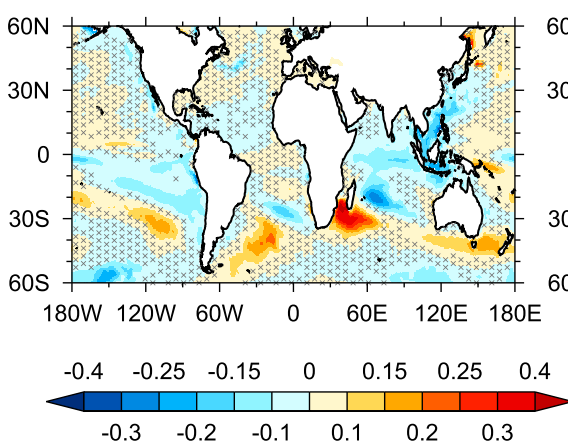

b) nino34+, AL north

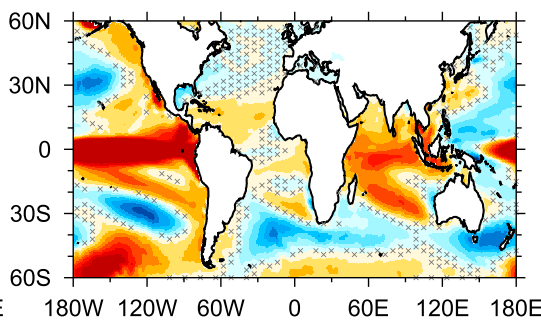

e) nino34+, AL south

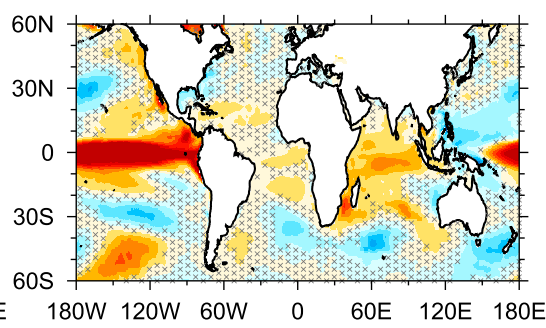

c) nino34+/SIOD-, AL north

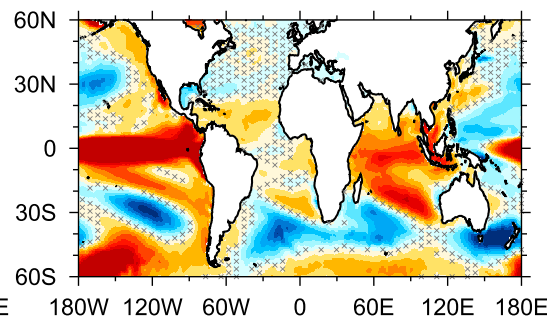

f) nino34+/SIOD-, AL south
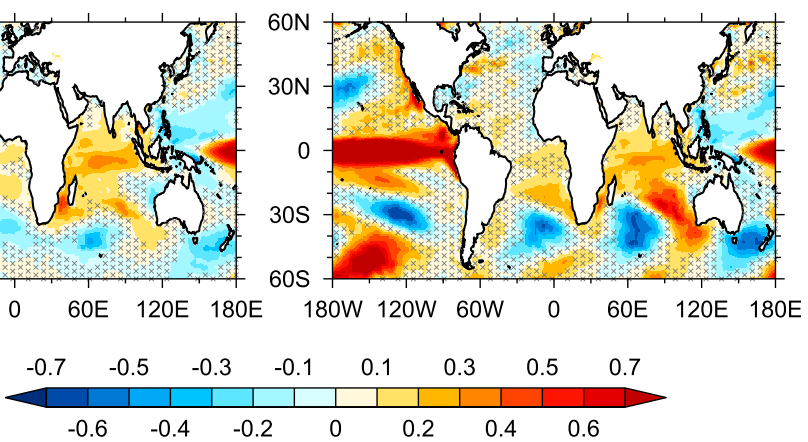

FIG. 10. January-February SST anomaly composites for LATv700 $<p_{33}$ (i.e., northward excursions of the Angola low) and (a) ENSO neutral, (b) $\Delta$ Niño-3.4 $>0.5 \mathrm{~K}$, (c) $\Delta$ Niño-3.4 $>0.5 \mathrm{~K}$ and SIOD $<-$ STDV. (d)-(f) As in (a)-(c), but for LATv700 $>p_{66}$ (i.e., southward excursions of the Angola low). Regions that are not statistically significant at the $5 \%$ level on the basis of a $t$ test are stippled. 

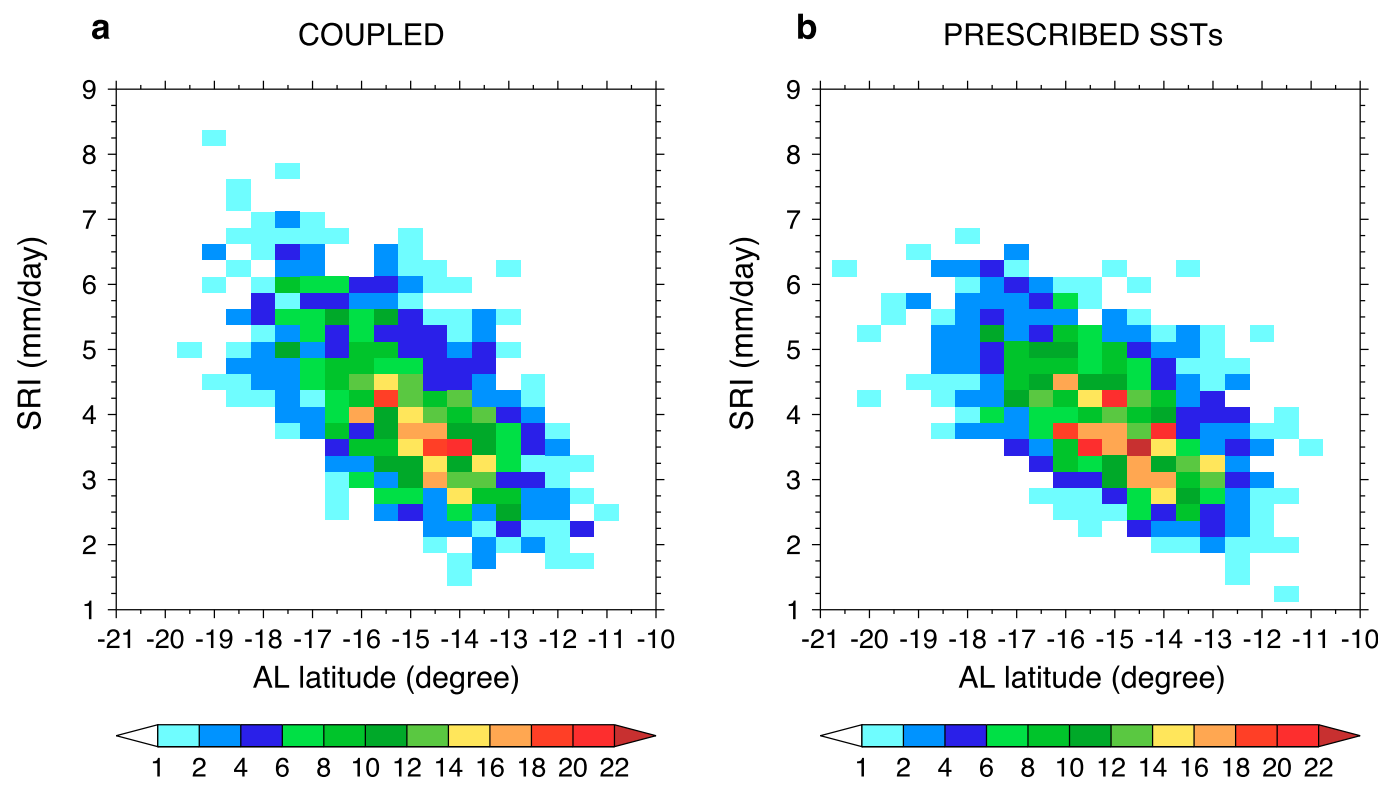

FIG. 11. Two-dimensional histogram of JFM SRI and LATv700 index (bin: $0.5^{\circ} \times 0.25 \mathrm{~mm} \mathrm{day}^{-1}$ ) for (a) coupled (LONG_FLOR-FA) and (b) uncoupled (FLOR_fixedSST) run. The last 900 years of LONG_FLOR-FA have been used.

flavors are not key in explaining different states of the Angola low. However, based on the amplitude of SST anomalies in Fig. 6, manifestations of El Niño with warmer tropical Indian Ocean are more common during north states of the Angola low, which are typically drier than average, consistent with previous studies (e.g., Nicholson 2003; Hoell et al. 2015). An Angola low anomalously displaced to the south is still possible in the El Niño/SIOD- composite providing that the SIOD dipole is shifted eastward (Fig. 10f). Localized positive SST anomalies between the eastern SA coast and Madagascar, common to ENSO neutral years (Fig. 10d), El Niño years (Fig. 10e), and El Niño/negative SIOD years (Fig. 10f), are consistent with the correlation analysis in Fig. 9 and seem to be an important driver of the Angola low variability.

\section{b. Role of land memory}

The relatively low correlation values between the Angola low position (strength) and SST anomalies (Fig. 9), and the modest differences between SST anomalies during the north and south states of the Angola low (Fig. 10), lead us to hypothesize that a relevant part of its interannual variability is unrelated to SST anomalies. Memory inherent in the land surface state or internal low-frequency extratropical atmospheric variability may therefore be responsible for the Angola low anomalous states. Although land memory, especially in semiarid regions, can extend up to 2 months (Beljaars et al. 1996; Fennessy and Shukla 1999; Schlosser and Milly 2002), this memory is relatively short-fewer than 15 days-for SA at the core of the wet season (e.g., Fig. 6 in Dirmeyer et al. 2009). Lagged composites ( 1 and 2 months) of soil moisture and precipitation anomalies for years in which the Angola low is in a north or south state are statistically insignificant and close to zero over most of SA (not shown). Land memory thus plays no role in determining the interannual variations of the Angola low in the LONG_FLOR-FA experiment.

\section{c. Role of internal atmospheric variability}

Finally, we examine the role of atmospheric internal variability unrelated to coupled atmosphere-ocean SST modes. We compare the Angola low latitudinal position LATv700 and SRI in the last 1000 years of LONG FLOR-FA to those in FLOR_fixedSST, an uncoupled 1000-yr run with prescribed annual cycle of SSTs obtained by averaging the last 900 years of LONG_FLORFA (Table 1). The distribution of SRI and LATv700 in Fig. 11 shows that the latitudinal range of LATv700 is slightly impacted by the lack of atmosphere-ocean coupled modes $\left(11^{\circ}-19.5^{\circ} \mathrm{S}\right.$ for the coupled model versus $11^{\circ}$ $20.5^{\circ} \mathrm{S}$ for prescribed SSTs). Along with the analyses in previous sections, this unambiguously demonstrates that large interannual variations of the Angola low exist even without the forcing of coupled atmosphere-ocean SST anomalies, and therefore they must be intrinsically determined by atmospheric internal variability. While the absence of El Niño does not seem to reduce the number of very dry years, a reduction in the upper limit of SRI (i.e., in the number of extremely wet years) does instead 


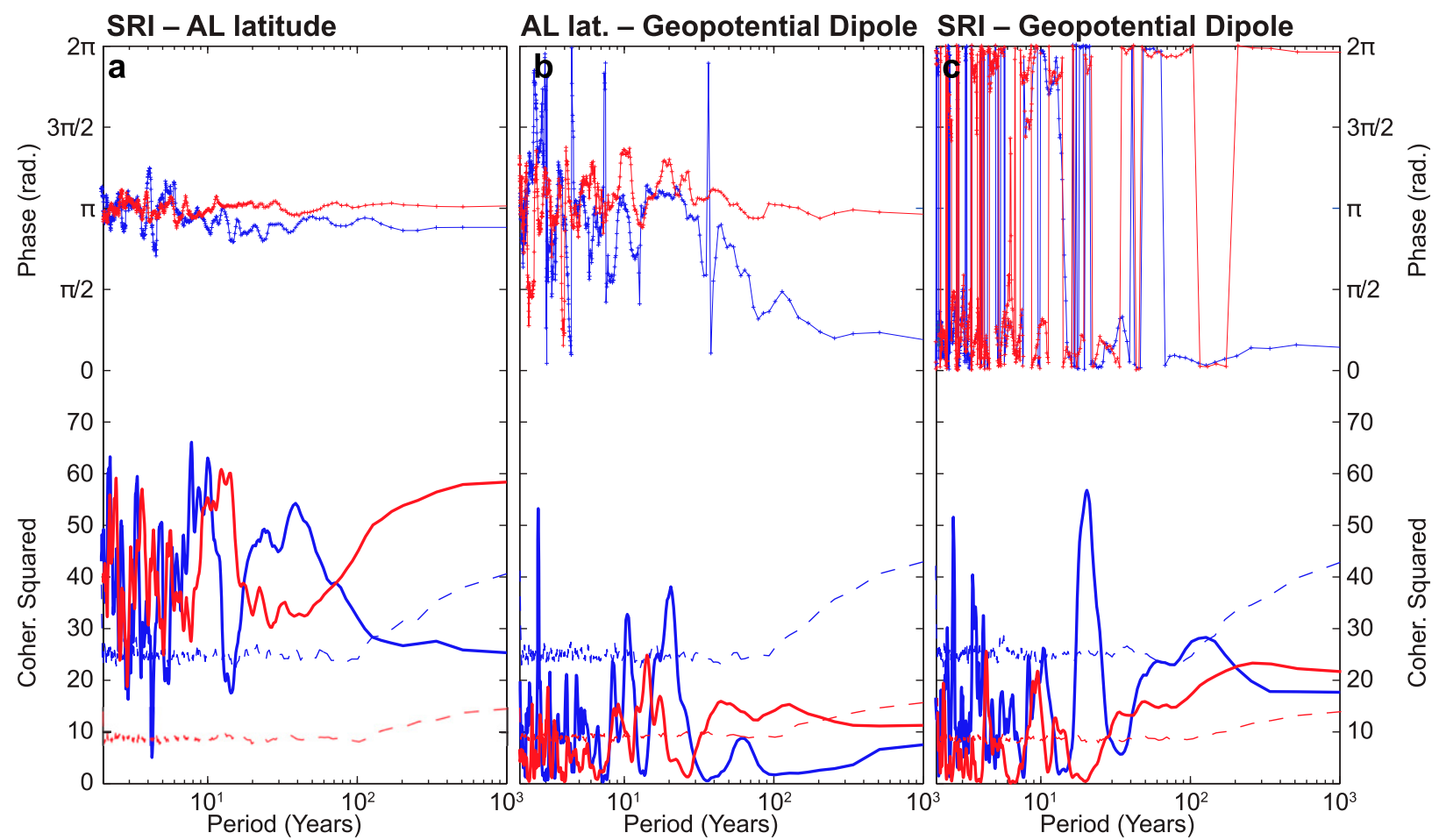

FIG. 12. Square coherence (\%) between (a) SRI and LATv700, (b) LATv700 and $\Delta z_{200}$, and (c) SRI and $\Delta z_{200}$ for the LONG_FLORFA (red) and FLOR_fixedSST (blue) experiments. Analysis is carried out on normalized data for the January-February means. Solid line with plus signs denote the phase relationship in radians. Dashed lines indicate the $95 \%$ level according to 1000 random time series obtained as permutations of the original time series, and having the same lag- 1 serial correlation.

occur, which suggests the nonlinearity of the association between ENSO and SA summer rainfall.

The spectral analysis of SRI and LATv700 from FLOR_fixedSST (see Fig. 12) further confirms that even in the absence of atmosphere-ocean coupling, the LATv700 and SRI feature considerable interannual-todecadal variability and elevated squared coherence (0.6), similarly to the spectrum of LATv700 and SRI in LONG_FLOR-FA (Fig. 8).

\section{d. Upper-level stationary wave patterns}

We next consider composites of the north, south, and "intermediate" Angola low states (section 2b). We then examine the anomalies of the stationary waves in the south composites relative to the intermediate state composites. Since tropical heating occurring in association with El Niño events affect the equator-pole temperature difference and hence the westerlies in the Southern Hemisphere, we further subdivide the north/south/intermediate composites into ENSO neutral and El Niño subcomposites. To elucidate to what degree the Angola low variability derives from internal atmospheric variability, we extend the analysis to the FLOR_fixedSST experiment, in which stationary Rossby waves cannot be excited by diabatic heating arising from SST anomalies associated with atmosphere-ocean coupled modes.

On the Southern Hemisphere scale, Fig. 13 displays the 200- and 700-hPa DJF anomalous stationary waves. Comparison of Figs. 13a and $13 \mathrm{~b}$ reveals a negative height anomaly centered over southern South America common to both the El Niño and ENSO neutral composites. Downstream of this negative anomaly, Figs. 13a and $13 \mathrm{~b}$ are suggestive of an anomalous stationary wave pattern extending across the South Atlantic into subtropical SA. Comparison with anomalies at $700 \mathrm{hPa}$ highlights a broadly barotropic structure over the South Atlantic, and a baroclinic structure over the SA land, with a negative height anomaly centered at roughly $20^{\circ} \mathrm{S}$, $20^{\circ} \mathrm{W}$ which is indicative of an Angola low displaced to the south of its climatological position (Figs. 13d-f). Some of the features of this anomalous stationary wave pattern are similar to the stationary wave pattern observed in January-March (JFM) 1998 (Lyon and Mason 2007). The anomalous stationary wave pattern in Figs. $13 \mathrm{a}$ and $13 \mathrm{~b}$ thus may be a general feature of the Southern Hemisphere atmosphere when the Angola low is abnormally displaced to the south. The anomalous stationary wave train associated with the Angola low 
a) ENSO neutral: $A L$ south-interm., $200 \mathrm{hPa}$

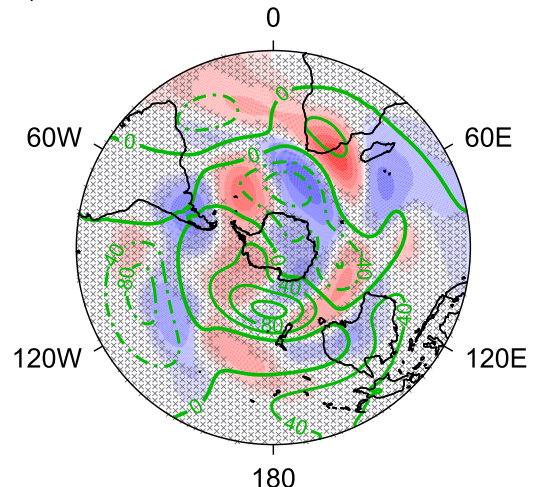

d) ENSO neutral: AL south-interm., $700 \mathrm{hPa}$

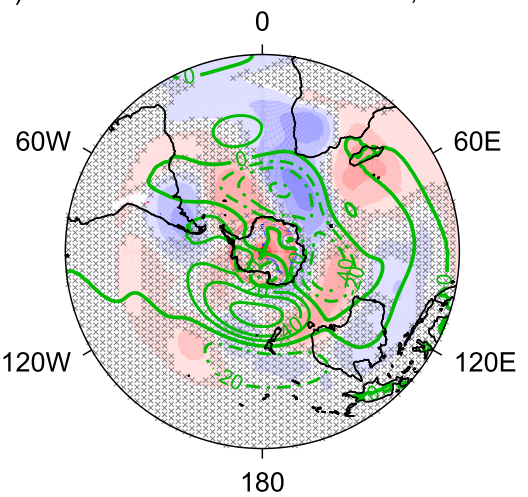

b) El Nino: AL south-interm., 200hPa

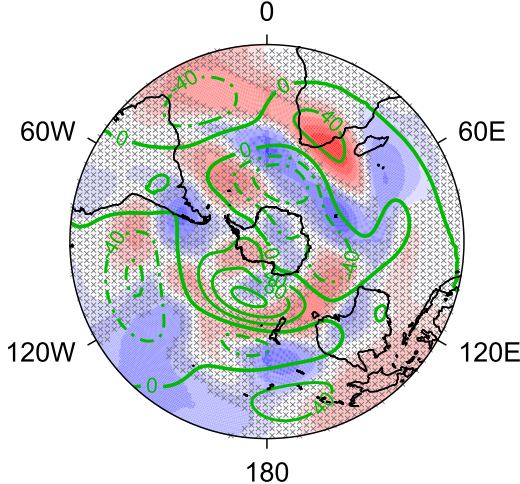

e) El Nino: AL south-interm., $700 \mathrm{hPa}$

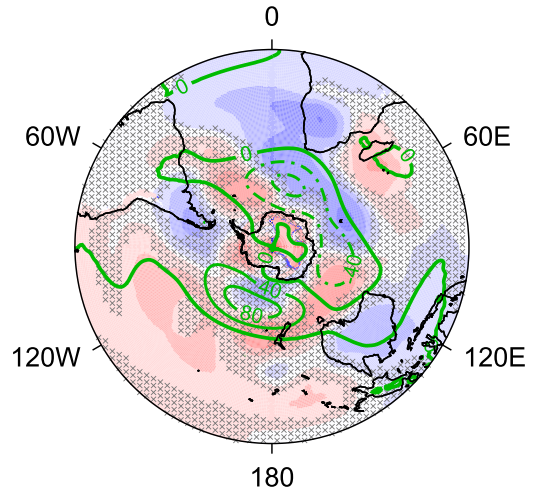

c) UNCOUPLED: AL south-interm., $200 \mathrm{hPa}$ 0

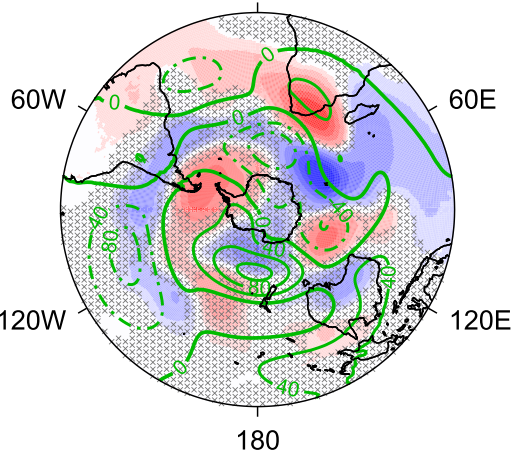

f) UNCOUPLED: AL south-interm., $700 \mathrm{hPa}$ 0

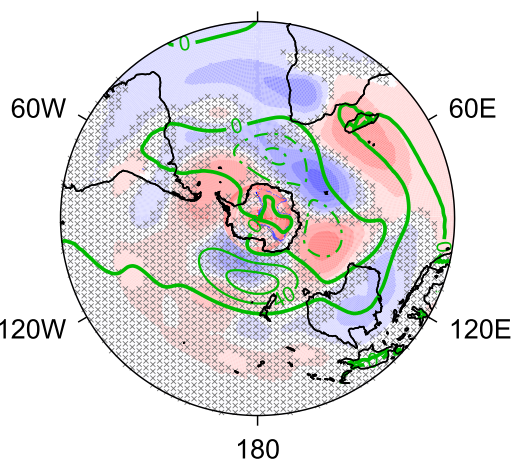

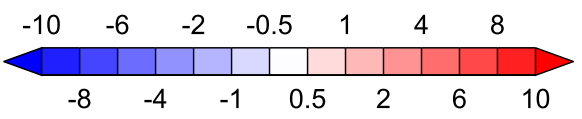

FIG. 13. South minus intermediate Angola low composite differences of anomalous DJF 200-hPa stationary waves (color shading) for (a) ENSO neutral conditions, (b) El Niño (both from LONG_FLOR-FA) conditions, and (c) from the uncoupled FLOR_fixedSST runs. South and intermediate state of the Angola low are defined as those with LATv700 below the first tercile, and between the first and second tercile of LATv700, respectively. Green contours denote the stationary waves of the intermediate composite. (d)-(f) As in (a)-(c), but at $700 \mathrm{hPa}$. Regions that are not statistically significant at the $5 \%$ level on the basis of a $t$ test are stippled.

north state (Fig. S9) has similar characteristics to that in Fig. 13 but reversed polarity. Notably, apart from minor details, these patterns are very similar in both the El Niño and ENSO neutral composite. We thus speculate that these waves are unlikely to be generated by tropical heating anomalies in the central-eastern Pacific associated with ENSO, as also confirmed by the uncoupled run.

The numerical and observational work by Berbery et al. (1992) shows that upper-level stationary Rossby waves from the South Atlantic to SA are observed during the austral summer and can be numerically reproduced by placing a wave source in proximity of southern South America [Figs. 6f,h of Berbery et al. (1992)]. Comparison between the coupled and uncoupled experiments (Figs. 13a-c) shows a generally less defined wave pattern over the South Atlantic, but very similar anomaly pattern over SA and southwestern Indian Ocean. The boomerang shaped negative anomaly over the southwestern Indian Ocean encircling the positive height anomaly over SA (visible in Figs. 13a-c) is compatible with the upstream development of upper-level stationary Rossby waves generated in the southern Indian Ocean [Fig. 6b of Berbery et al. (1992)]. The composite analysis displayed in Fig. 13 is thus suggestive of two different stationary Rossby wave trains, one originating upstream over southern South America and one downstream over southern Indian Ocean, both capable of affecting the Angola low mean state. A distinction between the two would require an in-depth understanding of the generation and dynamics of these wave patterns, which goes beyond the scope of the current investigation and it will be addressed in future research.

The less developed South Atlantic anomalous wave train in the FLOR_fixedSST composite (Figs. 13a,c) suggests that this may be modified by SST anomalies in 
a) ENSO neutral: AL south-interm., $200 \mathrm{hPa}$

b) El Nino: AL south-interm., 200hPa

c) UNCOUPLED: AL south-interm., 200hPa
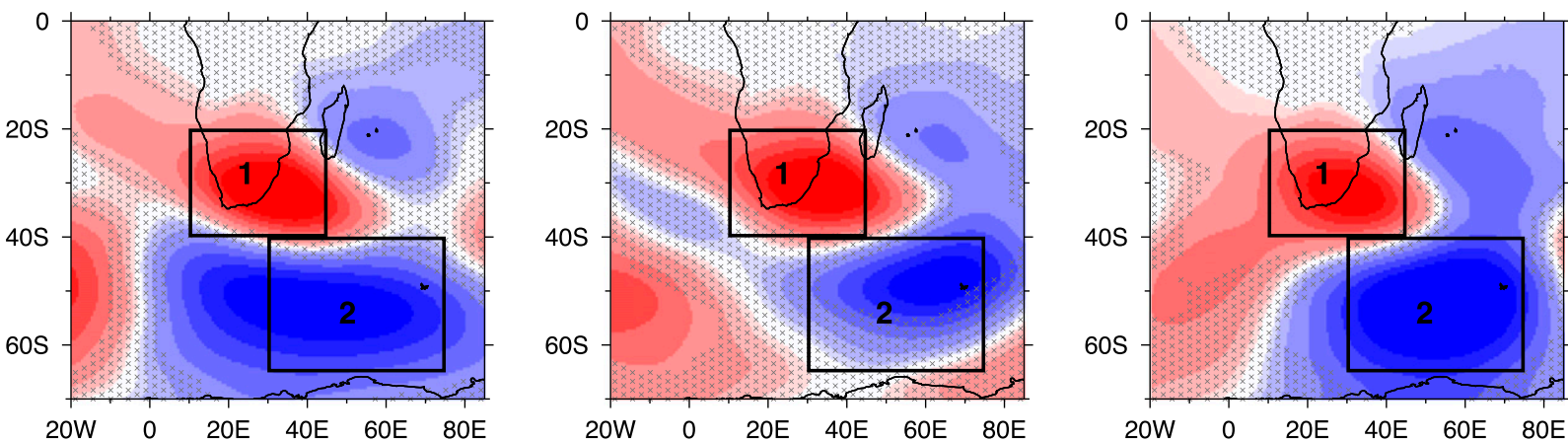

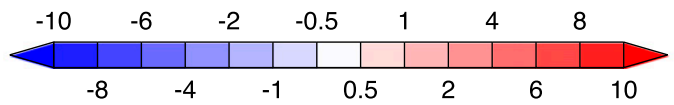

FIG. 14. Regional detail of the anomalous (strong minus intermediate) 200-hPa stationary waves (m) as in Fig. 13, showing the two regions used to calculate the dipole index $\Delta z_{200}$ (Table 2). Regions that are not statistically significant at the $5 \%$ level on the basis of a $t$ test are stippled.

the southwestern South Atlantic. Indeed, Fig. 10 shows that SST anomalies in the southwestern South Atlantic are generally higher when the Angola low is displaced to the south, both during neutral and active phases of ENSO. Similar conclusions are reached in terms of the strength of the Angola low cyclonic circulation (i.e., v700; Fig. S10).

To quantify the influence of the atmospheric wave train shown in Fig. 13 on the Angola low, we introduce a simple index, $\Delta z_{200}$, defined as the difference of the areaaveraged $200-\mathrm{hPa}$ stationary wave geopotential height between regions 1 and 2 (defined in Fig. 14). While empirical, this index captures the strong dipolar structure of the geopotential height anomalies over and south of SA associated with displaced states of the Angola low, with region 1 and 2 grossly corresponding to the positive and negative anomalies, respectively. Cross-spectral analysis between $\Delta z_{200}$, LATv700 and SRI (Fig. 12) shows that in FLOR_fixedSST the square coherence between $\Delta z_{200}$ and LATv700 (SRI) has statistically significant peaks at periods of 2-3 years and at the decadal time scale, with values of about $0.55(0.5)$ and $0.4-0.5$ (0.6), respectively. In other terms, about half of the variance of the Angola low latitudinal position and summer rainfall (SRI) is explained by extratropical stationary waves. If we extend this analysis for the coupled atmosphere-ocean case (LONG_FLOR-FA), these associations are considerably weakened to about $0.2-0.3$, although they remain statistically significant. This demonstrates that, while the Angola low is to a large extent intrinsically controlled by extratropical internal atmospheric variability, the atmospheric response forced by SST anomalies, which is weak but significant
(Fig. 9), lessens the influence of extratropical variability on the Angola low.

\section{Discussion and conclusions}

The tropical Angola low has recently been reevaluated as a major driver of intermodel, interannual and intraseasonal variability for subtropical SA summer rainfall (e.g., Munday and Washington 2017; Crétat et al. 2019; Howard and Washington 2018). Previous observational and modeling studies found evidence that anomalous states of the Angola low can strongly modulate subtropical SA summer rainfall (Cook et al. 2004; Reason and Jagadheesha 2005), and lead to major departures from drought conditions typically expected during El Niño (as in JFM 1998, Lyon and Mason 2007). However, the scarcity of atmospheric data over the SA region and the relatively small number of nonstandard El Niño years on records has hindered the progress toward a full understanding of what controls the interannual variability of the Angola low.

Here we have investigated the controls of the Angola low interannual variability using long-term numerical simulations performed with a comprehensive GCM (FLOR). This allowed us to have robust statistics of the Angola low states and to evaluate to what degree these are influenced by ENSO and other modes of variability. The FLOR model simulates well some key features of the SA climate, thus providing a novel source of insight to study SA climate. We find that when the Angola low is anomalously displaced to the south of its climatological latitudinal position, subtropical SA experiences above-average precipitation. Even during an El Niño 
or El Niño/SIOD-, typically expected droughts conditions do not materialize if the Angola low is displaced to the south of its climatological position (Fig. 6). While our study cannot rigorously demonstrate causality, it is likely that, at the seasonal time scale, the persistent anomalous position of the Angola low drives the persistent anomalies in precipitation, by impacting the direction and the magnitude of moisture fluxes from tropical SA and the Indian Ocean converging over land (Fig. 5). In fact, given the short land memory (i.e., less than two weeks) associated with soil moisture in summertime (Dirmeyer et al. 2009), it is unlikely that rainfall itself can drive the persistence in the anomalous states of Angola low for one to several months.

Our study shows that a complex variety of atmospheric and oceanic drivers can contribute to anomalous states of the Angola low, while it would seem to exclude prolonged (i.e., 1 month or longer) land-memory effects associated with land surface-atmosphere interactions (consistent with observations; see, e.g., Fig. 6 in Dirmeyer et al. 2009). In particular, spectral and regression analysis (Figs. 8, 9) confirms a weak yet statistically significant association between ENSO and the latitudinal position of the Angola low, whereas the SIOD phases play a lesser role (Fig. 7). A significant negative correlation is also found between the Angola low latitudinal position and the SST anomalies localized between the eastern coast of SA and southeastern Madagascar (Fig. 11), implying that higher SSTs within this region are associated with an Angola low more displaced to the south of its climatological position. Positive SST anomalies in this region are also found during El Niño years with a stronger Angola low and above-average precipitation over subtropical SA (Fig. 10). These findings are consistent with the modeling study of Reason (2002), who showed that warm SST anomaly close to the southern African coast produce a larger positive precipitation anomaly over SA. They also support the idea that SST anomalies in proximity of the east coast of SA are more efficient in affecting SA rainfall, contrary to the classical SIOD pattern as described in Behera and Yamagata (2001).

Comparison of the coupled run with a 1000-yr run driven by climatological SSTs reveals that the Angola low undergoes interannual displacements as large as in the coupled run. In both cases, the displacements associated with geopotential height anomalies over the southern Atlantic and Indian Ocean related to extratropical atmospheric variability. We find statistically robust evidence that upper-level anomalous stationary Rossby waves emanating from the southern South America are responsible for seasonal southern shifts of the Angola low (Fig. 13; Berbery et al. 1992). The location, extent and structure of these extratropical wave trains (Fig. 13) do not vary substantially from ENSO neutral to El Niño years. This agrees with the conclusions reached by Lyon and Mason $(2007,2009)$ specifically for JFM 1998, and further support the notion that internal atmospheric extratropical variability is partly responsible of the Angola low low-frequency variability. A quantification of the effect through cross spectral analysis reveals that midlatitude atmospheric variability explains almost $60 \%$ of the variance of the Angola low variability in the uncoupled run, but only $20 \%$ in the coupled run. Therefore, while the Angola low appears to be intrinsically controlled by atmospheric extratropical variability, the interference of the atmospheric response to tropical sea surface temperature anomalies considerably weakens this influence.

This study highlights that the interannual variability of the Angola low is determined by a nontrivial interaction of low-frequency extratropical atmospheric variability and tropical and subtropiclal SST anomalies. This poses a challenge to subseasonal and seasonal prediction of summertime rainfall over subtropical southern Africa. Future research in which the generation mechanisms and predictability of these upper-level anomalous stationary Rossby waves is examined, along with mechanistic studies to better understanding the interaction of these with tropical SST variability, is needed to reduce uncertainty of seasonal forecasts and future projections of southern Africa precipitation.

Acknowledgments. This manuscript was prepared under Award NA14OAR4320106 from the National Oceanic and Atmospheric Administration, U.S. Department of Commerce. The statements, findings, conclusions, and recommendations are those of the authors and do not necessarily reflect the views of the National Oceanic and Atmospheric Administration, or the U.S. Department of Commerce. We are grateful for the comments of two anonymous reviewers on this manuscript. We also thank Fanrong Zeng, who provided the ncl code to calculate the velocity potential; Nathanial Johnson, Xiasong Yang, and Thomas Delworth for their feedback on the first version of this manuscript; and Andrew Wittenberg for useful clarifications about ENSO.

\section{REFERENCES}

Barcikowska, M. J., S. B. Kapnick, and F. Feser, 2018: Impact of large-scale circulation changes in the North Atlantic sector on the current and future Mediterranean winter hydroclimate. Climate Dyn., 50, 2039-2059, https://doi.org/10.1007/s00382017-3735-5.

Behera, S. K., and T. Yamagata, 2001: Subtropical SST dipole events in the southern Indian Ocean. Geophys. Res. Lett., 28, 327-330, https://doi.org/10.1029/2000GL011451. 
Beljaars, A. C., P. Viterbo, M. J. Miller, and A. K. Betts, 1996: The anomalous rainfall over the United States during July 1993: Sensitivity to land surface parameterization and soil moisture anomalies. Mon. Wea. Rev., 124, 362-383, https://doi.org/ 10.1175/1520-0493(1996)124<0362:TAROTU>2.0.CO;2.

Beraki, A., D. DeWitt, W. Landman, and C. Olivier, 2014: Dynamical seasonal climate prediction using an ocean-atmosphere coupled climate model developed in partnership between South Africa and the IRI. J. Climate, 27, 1719-1741, https://doi.org/ 10.1175/JCLI-D-13-00275.1.

Berbery, E. H., J. N. Paegle, and J. D. Horel, 1992: Wavelike Southern Hemisphere extratropical teleconnections. J. Atmos. Sci., 49, 155-177, https://doi.org/10.1175/1520-0469(1992)049<0155: WSHET $>2.0 . \mathrm{CO} ; 2$.

Berrisford, P., P. Kallberg, S. Kobayashi, D. Dee, S. Uppala, A. J. Simmons, P. Poli, and H. Sato, 2011a: Atmospheric conservation properties in ERA-Interim. Quart. J. Roy. Meteor. Soc., 137, 1381-1399, https://doi.org/10.1002/qj.864.

- , and Coauthors, 2011b: The ERA-Interim archive, version 2.0. ERA Rep. Series 1, Tech. Rep., ECMWF, 23 pp.

Blamey, R. C., S. R. Kolusu, P. Mahlalela, M. C. Todd, and C. J. C. Reason, 2018: The role of regional circulation features in regulating El Niño climate impacts over southern Africa: A comparison of the 2015/2016 drought with previous events. Int. J. Climatol., 38, 4276-4295, https://doi.org/10.1002/joc.5668.

Capotondi, A., and Coauthors, 2015: Understanding ENSO diversity. Bull. Amer. Meteor. Soc., 96, 921-938, https://doi.org/ 10.1175/BAMS-D-13-00117.1.

Conway, D., and Coauthors, 2015: Climate and southern Africa's water-energy-food nexus. Nat. Climate Change, 5, 837-846, https://doi.org/10.1038/nclimate2735.

Cook, C., C. J. C. Reason, and B. C. Hewitson, 2004: Wet and dry spells within particularly wet and dry summers in the South African summer rainfall region. Climate Res., 26, 17-31, https://doi.org/10.3354/cr026017.

Cook, K. H., 2000: The South Indian convergence zone and interannual rainfall variability over southern Africa. J. Climate, 13, 3789-3804, https://doi.org/10.1175/1520-0442(2000)013<3789: TSICZA $>2.0 . \mathrm{CO} ; 2$.

Crétat, J., B. Pohl, B. Dieppois, S. Berthou, and J. Pergaud, 2019: The Angola Low: Relationship with southern African rainfall and ENSO. Climate Dyn., 52, 1783-1803, https://doi.org/ 10.1007/s00382-018-4222-3.

Dee, D. P., and Coauthors, 2011: The ERA-interim reanalysis: Configuration and performance of the data assimilation system. Quart. J. Roy. Meteor. Soc., 137, 553-597, https:// doi.org/10.1002/qj.828.

Delworth, T. L., and F. Zeng, 2014: Regional rainfall decline in Australia attributed to anthropogenic greenhouse gases and ozone levels. Nat. Geosci., 7, 583-587, https://doi.org/10.1038/ ngeo2201.

_- and Coauthors, 2012: Simulated climate and climate change in the GFDL CM2.5 high-resolution coupled climate model. J. Climate, 25, 2755-2781, https://doi.org/10.1175/JCLI-D-1100316.1.

_- F. Zeng, G. A. Vecchi, X. Yang, L. Zhang, and R. Zhang, 2016: The North Atlantic Oscillation as a driver of rapid climate change in the Northern Hemisphere. Nat. Geosci., 9, 509-512, https://doi.org/10.1038/ngeo2738.

Dieppois, B., M. Rouault, and M. New, 2015: The impact of ENSO on Southern African rainfall in CMIP5 ocean atmosphere coupled climate models. Climate Dyn., 45, 2425-2442, https:// doi.org/10.1007/s00382-015-2480-x.
- B. Pohl, M. Rouault, M. New, D. Lawler, and N. Keenlyside, 2016: Interannual to interdecadal variability of winter and summer southern African rainfall, and their teleconnections. J. Geophys. Res. Atmos., 121, 6215-6239, https://doi.org/ 10.1002/2015JD024576.

Dirmeyer, P. A., C. Schlosser, and K. Brubaker, 2009: Precipitation, recycling, and land memory: An integrated analysis. J. Hydrometeor., 10, 278-288, https://doi.org/10.1175/ 2008JHM1016.1.

Driver, P., B. Abiodun, and C. Reason, 2019: Modelling the precipitation response over southern Africa to the 2009-2010 El Niño using a stretched grid global atmospheric model. Climate Dyn., 52, 3929-3949, https://doi.org/10.1007/s00382-018-4362-5.

Fauchereau, N., B. Pohl, C. J. C. Reason, M. Rouault, and Y. Richard, 2009: Recurrent daily OLR patterns in the Southern Africa/southwest Indian Ocean region, implications for South African rainfall and teleconnections. Climate Dyn., 32, 575-591, https://doi.org/10.1007/s00382-008-0426-2.

Fennel, W., 1999: Theory of the Benguela upwelling system. J. Phys. Oceanogr., 29, 177-190, https://doi.org/10.1175/15200485(1999)029<0177:TOTBUS > 2.0.CO;2.

Fennessy, M. J., and J. Shukla, 1999: Impact of initial soil wetness on seasonal atmospheric prediction. J. Climate, 12, 3167-3180, https://doi.org/10.1175/1520-0442(1999)012<3167: IOISWO $>2.0 . \mathrm{CO} ; 2$.

Goddard, L., and N. E. Graham, 1999: Importance of the Indian Ocean for simulating rainfall anomalies over eastern and southern Africa. J. Geophys. Res., 104, 19099-19116, https:// doi.org/10.1029/1999JD900326.

Hoell, A., C. Funk, T. Magadzire, J. Zinke, and G. Husak, 2015: El Niño-Southern Oscillation diversity and southern Africa teleconnections during austral summer. Climate Dyn., 45, 15831599, https://doi.org/10.1007/s00382-014-2414-z.

- - - J. Zinke, and L. Harrison, 2017: Modulation of the Southern Africa precipitation response to the El Niño Southern Oscillation by the subtropical Indian Ocean Dipole. Climate Dyn., 48, 2529-2540, https://doi.org/10.1007/s00382-016-3220-6.

Howard, E., and R. Washington, 2018: Characterizing the synoptic expression of the Angola low. J. Climate, 31, 7147-7165, https://doi.org/10.1175/JCLI-D-18-0017.1.

Huang, B., and Coauthors, 2017: Extended Reconstructed Sea Surface Temperature, Version 5 (ERSSTv5): Upgrades, validations, and intercomparisons. J. Climate, 30, 8179-8205, https://doi.org/10.1175/JCLI-D-16-0836.1.

Hurley, J. V., and W. R. Boos, 2015: A global climatology of monsoon low-pressure systems. Quart. J. Roy. Meteor. Soc., 141, 1049-1064, https://doi.org/10.1002/qj.2447.

Jia, L., and Coauthors, 2015: Improved seasonal prediction of temperature and precipitation over land in a high-resolution GDFL climate model. J. Climate, 28, 2044-2062, https:// doi.org/10.1175/JCLI-D-14-00112.1.

Johnson, N. C., 2013: How many ENSO flavors can we distinguish? J. Climate, 26, 4816-4827, https://doi.org/10.1175/JCLI-D-1200649.1.

Kapnick, S. B., T. L. Delworth, M. Ashfaq, S. Malyshev, and P. C. D. Milly, 2014: Snowfall less sensitive to warming in Karakoram than in Himalayas due to a unique seasonal cycle. Nat. Geosci., 7, 834-840, https://doi.org/10.1038/ngeo2269.

— , and Coauthors, 2018: Potential for western US seasonal snowpack prediction. Proc. Natl. Acad. Sci. USA, 115, 11801185, https://doi.org/10.1073/pnas.1716760115.

Kirtman, B. P., and Coauthors, 2014: The North American Multimodel Ensemble: Phase-1 seasonal-to-interannual predic- 
tion; Phase-2 toward developing intraseasonal prediction. Bull. Amer. Meteor. Soc., 95, 585-601, https://doi.org/10.1175/ BAMS-D-12-00050.1.

Landman, W. A., and A. Beraki, 2012: Multi-model forecast skill for mid-summer rainfall over southern Africa. Int. J. Climatol., 32, 303-314, https://doi.org/10.1002/joc.2273.

Lazenby, M., M. Todd, and Y. Wang, 2016: Climate model simulation of the South Indian Ocean convergence zone: Mean state and variability. Climate Res., 68, 59-71, https://doi.org/ 10.3354/cr01382.

Lindesay, J. A., 1988: South African rainfall, the southern oscillation and a southern hemisphere semi-annual cycle. J. Climatol., 8, 1730, https://doi.org/10.1002/joc.3370080103.

Lyon, B., and S. J. Mason, 2007: The 1997-98 summer rainfall season in southern Africa. Part I: Observations. J. Climate, 20, 5134-5148, https://doi.org/10.1175/JCLI4225.1.

— , and — 2009: The 1997-98 summer rainfall season in southern Africa. Part II: Model simulations and coupled model forecast. J. Climate, 22, 3802-3818, https://doi.org/10.1175/2009JCLI2600.1.

Marchant, R., C. Mumbi, S. Behera, and T. Yamagata, 2007: The Indian Ocean dipole-The unsung driver of climatic variability in East Africa. Afr. J. Ecol., 45, 4-16, https://doi.org/ 10.1111/j.1365-2028.2006.00707.x.

Misra, V., 2003: The influence of Pacific SST variability on the precipitation over southern Africa. J. Climate, 16, 2408-2418, https://doi.org/10.1175/2785.1.

Mo, K. C., and J. N. Paegle, 2001: The Pacific-South American modes and their downstream effects. Int. J. Climatol., 21, 1211-1219, https://doi.org/10.1002/joc.685.

Mulenga, H. M., 1998: Southern African climatic anomalies, summer rainfall and the Angola low. Ph.D. dissertation, University of Cape Town, South Africa, 232 pp.

Munday, C., and R. Washington, 2017: Circulation controls on southern African precipitation in coupled models: The role of the Angola Low. J. Geophys. Res. Atmos., 122, 861-877, https://doi.org/10.1002/2016JD025736.

— and - 2018: Systematic climate model rainfall biases over southern Africa: Links to moisture circulation and topography. J. Climate, 31, 7533-7548, https://doi.org/10.1175/JCLID-18-0008.1.

Nicholson, S. E., 2003: Comments on "The South Indian convergence zone and interannual rainfall variability over southern Africa" and the question of ENSO's influence on southern Africa. J. Climate, 16, 555-562, https://doi.org/10.1175/15200442(2003)016<0555:COTSIC $>2.0$.CO;2.

_- and D. Entekhabi, 1987: Rainfall variability in equatorial and southern Africa: Relationships with sea surface temperatures along the southwest coast of Africa. J. Climate Appl. Meteor., 26, 561-578, https://doi.org/10.1175/1520-0450(1987)026<0561: RVIEAS $>2.0 . C O ; 2$.

, and J. Kim, 1997: The relationship between El Niño and Southern Oscillation to African rainfall. Int. J. Climatol., 17, 117-135, https://doi.org/10.1002/(SICI)1097-0088(199702)17: $2<117::$ AID-JOC84>3.0.CO;2-O.

Nigam, S., and E. DeWeaver, 2003: Stationary waves (orographic and thermally forced). Encyclopedia of Atmospheric Sciences, J. R. Holton, Ed., Academic Press, 2121-2137, https://doi.org/ 10.1016/B0-12-227090-8/00381-X.

Pascale, S., S. Bordoni, S. B. Kapnick, G. A. Vecchi, L. Jia, T. L. Delworth, S. Underwood, and W. Anderson, 2016: The impact of horizontal resolution on North American monsoon Gulf of California moisture surges in a suite of coupled global climate models. J. Climate, 29, 7911-7936, https://doi.org/10.1175/ JCLI-D-16-0199.1.

—, W. R. Boos, S. Bordoni, T. L. Delworth, S. B. Kapnick, H. Murakami, G. A. Vecchi, and W. Zhang, 2017: Weakening of the North American monsoon with global warming. Nat. Climate Change, 7, 806-812, https://doi.org/10.1038/ nclimate3412.

Pohl, B., N. Fauchereau, Y. Richard, M. Rouault, and C. J. C. Reason, 2009: Interactions between synoptic, intraseasonal and interannual convective variability over southern Africa. Climate Dyn., 33, 1033-1050, https://doi.org/10.1007/s00382008-0485-4.

Pomposi, C., C. Funk, S. Shukla, L. Harrison, and T. Magadzire, 2018: Distinguishing southern Africa precipitation response by strength of El Niño events and implications for decisionmaking. Environ. Res. Lett., 13, 074015, https://doi.org/10.1088/ 1748-9326/aacc4c.

Rácz, Z., and R. K. Smith, 1999: The dynamics of heat lows. Quart. J. Roy. Meteor. Soc., 125, 225-252, https://doi.org/10.1002/ qj. 49712555313.

Ratnam, J. V., S. K. Behera, Y. Masumoto, and T. Yamagata, 2014: Remote effects of El Niño and Modoki events on the austral summer precipitation of southern Africa. J. Climate, 27, 38023815, https://doi.org/10.1175/JCLI-D-13-00431.1.

Reason, C. J. C., 2002: Sensitivity of the southern African circulation to dipole sea-surface temperature patterns in the south Indian Ocean. Int. J. Climatol., 22, 377-393, https://doi.org/ 10.1002/joc.744.

— , and D. Jagadheesha, 2005: A model investigation of recent ENSO impacts over southern Africa. Meteor. Atmos. Phys., 89, 181-205, https://doi.org/10.1007/s00703-005-0128-9.

_- W. Landman, and W. Tennant, 2006: Seasonal to decadal prediction of southern African climate and its links with variability of the Atlantic Ocean. Bull. Amer. Meteor. Soc., 87, 941-956, https://doi.org/10.1175/BAMS-87-7-941.

Rienecker, M. M., and Coauthors, 2011: MERRA: NASA's Modern-Era Retrospective Analysis for Research and Applications. J. Climate, 24, 3624-3648, https://doi.org/10.1175/ JCLI-D-11-00015.1.

Ropelewski, C. F., and M. S. Halpert, 1987: Global and regional scale precipitation patterns associated with $\mathrm{El}$ Niño/Southern Oscillation. Mon. Wea. Rev., 115, 1606-1626, https://doi.org/ 10.1175/1520-0493(1987)115<1606:GARSPP>2.0.CO;2.

Saji, N. H., B. N. Goswami, P. N. Vinayachandran, and T. Yamagata, 1999: A dipole mode in the tropical Indian Ocean. Nature, 401, 360-363, https://doi.org/10.1038/43854.

Schlosser, C. A., and P. C. D. Milly, 2002: A model-based investigation of soil moisture predictability and associated climate predictability. J. Hydrometeor., 3, 483-501, https://doi.org/ 10.1175/1525-7541(2002)003<0483:AMBIOS>2.0.CO;2.

Schneider, U., A. Becker, P. Finger, A. Meyer-Christoffer, M. Ziese, and B. Rudolf, 2014: GPCC's new land surface precipitation climatology based on quality-controlled in situ data and its role in quantifying the global water cycle. Theor. Appl. Climatol., 115, 15-40, https://doi.org/10.1007/s00704013-0860-x.

Siderius, C., K. E. Gannon, M. Ndiyoi, A. Opere, N. Batisani, D. Olago, J. Pardoe, and D. Conway, 2018: Hydrological response and complex impact pathways of the 2015/2016 El Niño in Eastern and Southern Africa. Earth's Future, 6, 2-22, https://doi.org/10.1002/2017EF000680.

Taylor, K. E., R. J. Stouffer, and G. A. Meehl, 2012: An overview of CMIP5 and the experiment design. Bull. Amer. Meteor. 
Soc., 93, 485-498, https://doi.org/10.1175/BAMS-D-1100094.1.

Trenberth, K. E., 1997: The definition of El Niño. Bull. Amer Meteor. Soc., 78, 2771-2777, https://doi.org/10.1175/15200477(1997)078<2771:TDOENO $>2.0$.CO;2.

Vecchi, G. A., and Coauthors, 2014: On the seasonal forecasting of regional tropical cyclone activity. J. Climate, 27, 7994-8016, https://doi.org/10.1175/JCLI-D-14-00158.1.

Vigaud, N., Y. Richard, M. Rouault, and N. Fauchereau, 2009: Moisture transport between the South Atlantic Ocean and southern Africa: Relationships with summer rainfall and associated dynamics. Climate Dyn., 32, 113-123, https://doi.org/ 10.1007/s00382-008-0377-7.

von Storch, H., and F. W. Zwiers, 2003: Statistical Analysis in Climate Research. Cambridge University Press, 496 pp.

Washington, R., and A. Preston, 2006: Extreme wet years over southern Africa: Role of Indian Ocean sea surface temperatures. J. Geophys. Res., 111, D15104, https://doi.org/10.1029/2005JD006724.

Wittenberg, A. T., and Coauthors, 2018: Improved simulations of tropical Pacific annual-mean climate in the GFDL FLOR and
HiFLOR coupled GCMs. J. Adv. Model. Earth Syst., 10, 31763220, https://doi.org/10.1029/2018MS001372.

Yang, X., and Coauthors, 2015: Seasonal predictability of extratropical storm tracks in GFDL's high-resolution climate prediction model. J. Climate, 28, 3592-3611, https://doi.org/ 10.1175/JCLI-D-14-00517.1.

Zhang, H., and T. Delworth, 2018: Detectability of decadal anthropogenic hydroclimate changes over North America. J. Climate, 31, 2579-2597, https://doi.org/10.1175/JCLI-D17-0366.1.

- — - F. Zeng, G. Vecchi, K. Paffendorf, and L. Jia, 2016: Detection, attribution, and projection of regional rainfall changes on (multi-) decadal time scales: A focus on southeastern South America. J. Climate, 29, 8515-8534, https:// doi.org/10.1175/JCLI-D-16-0287.1.

Zhang, Q., H. Körnich, and K. Holmgren, 2013: How well do reanalyses represent the southern African precipitation? Climate Dyn., 40, 951-962, https://doi.org/10.1007/s00382012-1423-z. 